\title{
USP28 deletion and small molecule inhibition destabilises c-Myc and elicits regression of squamous cell lung carcinoma
}

\begin{abstract}
E. Josue Ruiz ${ }^{1}$, Adan Pinto-Fernandez ${ }^{2}$, Andrew P. Turnbull ${ }^{3}$, Linxiang Lan ${ }^{1}$, Thomas M. Charlton ${ }^{2}$, Hannah Claire Scott ${ }^{2}$, Andreas Damianou ${ }^{2}$, George Vere ${ }^{2}$, Eva M. Riising ${ }^{1}$, Clive Da Costa ${ }^{1}$, Wojciech W. Krajewski ${ }^{3}$, David Guerin ${ }^{4,12}$, Jeffrey Kearns ${ }^{4,13}$, Stephanos loannidis ${ }^{4,14}$, Marie Katz ${ }^{4,15}$, Crystal McKinnon ${ }^{4,15}$, Jonathan C. O'Connell $^{4,15}$, Natalia Moncaut ${ }^{1}$, Ian Rosewell ${ }^{5}$, Emma Nye ${ }^{1}$, Neil Jones ${ }^{3}$, Claire Heride $^{3}$, Malte Gersch ${ }^{6}$, Min Wu ${ }^{16}$, Christopher J. Dinsmore ${ }^{4,17}$, Tim R. Hammonds ${ }^{3,18}$, Sunkyu Kim ${ }^{19}$, David Komander ${ }^{7}$, Sylvie Urbé ${ }^{8}$, Michael J. Clague ${ }^{9}$, Benedikt M. Kessler $^{2,20}$ and Axel Behrens ${ }^{1,9,10,11,20}$
\end{abstract}

${ }^{1}$ Adult stem cell laboratory; The Francis Crick Institute, 1 Midland Road, London NW1 1AT, UK

2 Target Discovery Institute, Nuffield Department of Medicine, University of Oxford, Roosevelt Drive, Oxford OX3 7FZ, UK

${ }^{3}$ CRUK Therapeutic Discovery Laboratories, The Francis Crick Institute, 1 Midland Road, London NW1 1AT, UK

${ }^{4}$ FORMA Therapeutics, Arsenal Street, Watertown, Massachusetts 02472, USA

${ }^{5}$ Genetic Manipulation Service, The Francis Crick Institute, 1 Midland Road, London NW1 1AT, UK

${ }^{6}$ Max Planck Institute of Molecular Physiology, Otto-Hahn-Str 11, 44227 Dortmund, Germany

${ }^{7}$ Ubiquitin Signalling Division, Walter and Eliza Hall Institute of Medical Research, Royal Parade, Parkville VIC 3052, and Dept of Medical Biology, University of Melbourne, VIC 3010, Australia

${ }^{8}$ Cellular and Molecular Physiology, Institute of Translational Medicine, University of Liverpool, Crown Street, Liverpool L69 3BX, UK

${ }^{9}$ Cancer Stem Cell Laboratory, Institute of Cancer Research, London, UK

${ }^{10}$ Imperial College, Division of Cancer, Department of Surgery and Cancer, London, UK

${ }^{11}$ Convergence Science Centre, Imperial College, London, SW7 2BU, UK

12 Present address: Constellation Pharmaceuticals, 215 First St, Cambridge, MA 02142, USA

13 Present address: Novartis Institutes for BioMedical Research, 250 Massachusetts Ave, Cambridge, MA 02139, USA

${ }^{14}$ Present address: H3 Biomedicine, 300 Technology Square, Cambridge, MA 02139, USA

15 Present address: Valo Health, 399 Boylston St, Suite 505, Boston, MA 02116, USA

${ }^{16}$ Present address: Disc Medicine, 150 Cambridgepark Drive Suite 103, Cambridge, MA 02135, USA

17 Present address: Kronos Bio, Inc., 301 Binney Street, 2nd Floor East, Cambridge, MA 02142, USA

${ }^{18}$ Present address: Locki Therapeutics, London Bioscience Innovation Centre, 2 Royal College Street, London NW1 0NH, UK

${ }^{19}$ Incyte, 1801 Augustine Cut-off, Wilmington, DE 19803, USA

20:

Benedikt M Kessler

Target Discovery Institute

University of Oxford

OX3 7FZ, UK

benedikt.kessler@ndm.ox.ac.uk
Axel Behrens

The Francis Crick Institute

London

NW1 AT, UK

axel.behrens@icr.ac.uk

Running title: Essential function of USP28 in squamous cell lung cancer 


\section{Abstract (188 words)}

2 Lung squamous cell carcinoma (LSCC) is a considerable global health burden, with

3 an incidence of over 600,000 cases per year. Treatment options are limited, and

4 patient 5 -year survival rate is less than $5 \%$. The ubiquitin specific protease 28 (USP28)

5 has been implicated in tumorigenesis through its stabilization of the oncoprotein c-

6 MYC. Here, we show that genetic inactivation of Usp28 induced regression of

7 established murine LSCC lung tumors. We developed a small molecule that inhibits

8 USP28 activity in the low nanomole range. While displaying cross-reactivity against

9 the closest homologue USP25, this inhibitor showed a high degree of selectivity over

10 other deubiquitinases. USP28 inhibitor treatment resulted in a dramatic decrease in c-

11 Myc proteins levels and consequently induced substantial regression of

12 autochthonous murine LSCC tumors and human LSCC xenografts, thereby

13 phenocopying the effect observed by genetic deletion. Thus, USP28 may represent a

14 promising therapeutic target for the treatment of squamous cell lung carcinoma. 


\section{Introduction}

2 Lung cancer is the leading cause of cancer death worldwide. Based on histological

3 criteria lung cancer can be subdivided into non-small cell lung cancer (NSCLC) and

4 the rarer small cell lung cancer. The most common NSCLCs are lung adenocarcinoma

5 (LADC) and squamous cell carcinoma (LSCC), with large cell carcinoma being less

6 commonly observed. Progress has been made in the targeted treatment of LADC,

7 largely due to the development of small-molecule inhibitors against EGFR, ALK, and

8 ROS1 (Cardarella and Johnson, 2013). However, no targeted treatment options exist

9 for LSCC patients (Hirsch et al., 2017; Novello et al., 2014). Consequently, despite

10 having limited efficacy on LSCC patient survival, platinum-based chemotherapy

11 remains the cornerstone of current LSCC treatment (Fennell et al., 2016; Isaka et al.,

12 2017; Scagliotti et al., 2008). Therefore, there is an urgent need to identify novel

13 druggable targets for LSCC treatment and to develop novel therapeutics.

14 The FBXW7 protein product F-box/WD repeat-containing protein 7 (FBW7) is the

15 substrate recognition component of an SCF-type ubiquitin ligase, which targets

16 several well-known oncoproteins, including c-Myc, Notch, and c-Jun, for degradation

17 (Davis et al., 2014). These oncoproteins accumulate in the absence of FBW7 function, and genetic analyses of human LSCC samples revealed common genomic alterations in FBXW7 (Cancer Genome Atlas Research, 2012; Kan et al., 2010). In addition, FBW7 protein is undetectable by immunohistochemistry (IHC) in $69 \%$ of LSCC patient 21 tumor samples (Ruiz et al., 2019). Genetically engineered mice harboring loss of

22 Fbxw7 concomitant with KRasG12D activation (KF mice) develop LSCC with 100\% 23 penetrance and short latency, as well as LADC (Ruiz et al., 2019). Thus, FBW7 is an 24 important tumor suppressor in both human and murine lung cancer. 
1 The deubiquitinase USP28 opposes FBW7-mediated ubiquitination of the

2 oncoproteins c-Myc and c-Jun, thereby stabilizing these proteins (Popov et al., 2007).

3 In a murine model of colorectal cancer, deleting Usp28 reduced size of established

4 tumors and increased lifespan (Diefenbacher et al., 2014). Therefore, targeting USP28

5 in order to destabilize its substrates represents an attractive strategy to inhibit the

6 function of c-Myc and other oncogenic transcription factors that are not amenable to

7 conventional inhibition by small molecules.

8 Here, we describe the characterisation of a novel USP28 inhibitory compound

9 (USP28i) and the genetic as well as chemical validation of USP28 as a promising

10 therapeutic target for LSCC tumors. Using an FRT/FLP and CRE/LOXP dual

11 recombinase system (Schonhuber et al., 2014), we show that Usp28 inactivation in

12 established LSCC results in dramatic tumor regression. Importantly, USP28i treatment

13 recapitulates LSCC regression in both mouse models and human LSCC xenografts.

14 Absence or inhibition of USP28 resulted in a dramatic decrease in the protein levels

15 of c-Myc, providing a potential mechanism of action for USP28i. Therefore, USP28

16 inhibition should be a strong candidate for clinical evaluation, particularly given the

17 paucity of currently available therapy options for LSCC patients. 


\section{Results}

2 USP28 is required to maintain protein levels of c-Myc, c-Jun and $\Delta$ p63 in LSCC

3 To gain insights into the molecular differences between LADC and LSCC, we

4 investigated the expression of MYC in these common NSCLCs subtypes. MYC was

5 transcriptionally upregulated in human LSCC compared to healthy lung tissue or LADC tumors (Figure 1A). Quantitative polymerase chain reaction (qPCR) analysis on an independent set of primary human lung biopsy samples confirmed that MYC is highly expressed in LSCC tumors compared with normal lung tissue (Figure 1B).

9 Moreover, immunohistochemistry (IHC) staining on primary lung tumors confirmed a significant abundance of c-Myc protein in LSCC samples (Figure 1C, 1D). Also $\Delta p 63$ and c-Jun, critical factors in squamous cell identity and tumor maintenance, respectively, showed higher protein levels in LSCC compared to LADC tumors (Figure 1C, 1D). Individual downregulation of $\mathrm{c}-\mathrm{Myc}, \mathrm{C}-\mathrm{Jun}$ and $\Delta \mathrm{p} 63$ by siRNA resulted in a significant reduction of cell growth in four independent human LSCC cell lines (Figure 1E, S1A-C).

As c-Myc, c-Jun and $\Delta \mathrm{p} 63$ protein levels are controlled by the deubiquitinase USP28

17 (Popov et al., 2007; Prieto-Garcia et al., 2020), we analysed its expression in publicly available datasets (The Cancer Genome Atlas). We observed that $25 \%$ of human LSCC cases show gain-of-function alterations in USP28 (Figure 1F). In addition, a positive correlation between USP28 copy-number and mRNA expression was found in the same datasets (Figure S2A). Interestingly, qPCR and IHC analysis on human LSCC samples revealed that low USP28 mRNA levels correlated with low USP28 protein levels and likewise, high/moderate mRNA levels also correlated with high USP28 protein levels (Figure 1G, S2B). Since USP28 is involved in $\Delta p 63$, c-Jun and c-Myc stabilization and higher expression of USP28 is associated with a significantly 
1 shorter survival time (Prieto-Garcia et al., 2020), we targeted its expression. Usp28

2 downregulation by shRNA resulted in a significant reduction in c-Myc, c-Jun and $\Delta$ p63

3 protein levels in LSCC primary tumor cells and reduced LSCC cell growth (Figure 1H,

4 1I). Thus, targeting USP28 in order to destabilize its substrates represents a rational

5 strategy to target tumor cells that rely on oncogenic transcription factors that are

6 currently not druggable by small molecules.

\section{Generation of a pre-clinical dual recombinase lung cancer mouse model}

9 Recently, Usp28 was shown to be required for the initiation of lung tumors in the

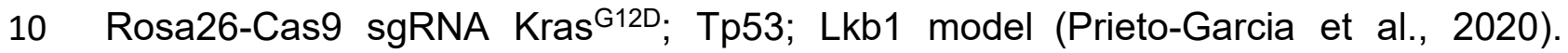
However, a meaningful pre-clinical model requires targeting the therapeutic candidate gene in existing growing lung tumors. Thus, to assess the function of Usp28 in established tumors, we developed a new genetically engineered mouse (GEM) model to temporally and spatially separate tumor development from target deletion by using two independent recombinases: Flp and Cre ${ }^{\text {ERT }}$. In this model, LSCC and LADC formation is initiated by KRas ${ }^{\mathrm{G} 12 \mathrm{D}}$ activation and Fbxw7 deletion using Flp recombinase, and the Cre/loxP system can then be used for inactivation of Usp28 flox/flox in established tumors. To allow conditional FRT/FIp-mediated inactivation of Fbxw7

19 function, we inserted two FRT sites flanking exon 5 of the endogenous Fbxw7 gene in 20 mice to generate a Fbxw7 $7^{\text {FRT/FRT }}$ allele that can be deleted by Flp recombinase (Figure 21 S3A, S3B). Expression of Flp recombinase resulted in the deletion of Fbxw7 exon 5, 22 which could be detected by PCR (Figure S3B). The resulting strain, Fbxw7FRT/FRT, was crossed to FRT-STOP-FRT (FSF)-KRas ${ }^{\mathrm{G} 12 \mathrm{D}}$ mice to generate FSF-KRas ${ }^{\mathrm{G} 12 \mathrm{D}}$; 24 Fbxw7 $7^{\text {FRT/FRT }}$ (KF-Flp model). 
1 USP28 is an effective therapeutic target for LSCC, but not KRas ${ }^{\text {G12D; }}$ Trp53

2 mutant LADC tumors

3 The KF-Flp strain described above was crossed with ROSA26-FSF-Cre ${ }^{\text {ERT; }}$

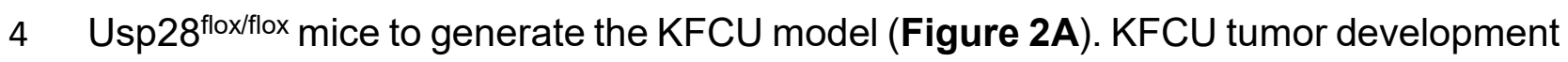

5 was monitored by CT scans. At ten-to-eleven weeks post-infection with Flp

6 recombinase-expressing recombinant adenoviruses, animals displayed lesions in

7 their lungs. At this time point, we confirmed by histology that KFCU mice develop both

8 LADC and LSCC tumors (Figure S3C). As expected (Ruiz et al., 2019), KFCU LADC

9 lesions occurred in alveolar tissue and were positive for Sftpc and TTF1. KFCU LSCC

10 tumors occurred mainly in bronchi (rarely manifesting in the alveolar compartment) and expressed $\mathrm{CK} 5$ and $\Delta \mathrm{p} 63$. Next, animals displaying lung tumors were exposed to tamoxifen to activate the Cre ${ }^{\mathrm{ERT}}$ protein and delete the conditional Usp28 floxed alleles (Figure 2A, S3D). Although the loss of Usp28 expression decreased LADC tumor size, it did not reduce the number of LADC tumors (Figure 2B-D). In contrast, histological examination of KFCU mice revealed a clear reduction in the numbers of LSCC lesions in Usp28-deleted lungs (Figure 2F, S3D). As well as a significant reduction in tumor number, the few CK5-positive LSCC lesions that remained were substantially smaller than control tumors (Figure 2G). Measurement of the size of 429 individual KFCU LSCC tumors (326 vehicle-treated and 103 tamoxifen-treated) showed an average size of $11.4 \times 10^{4} \mu \mathrm{m}^{2}$ in the vehicle arm versus $4.6 \times 10^{4} \mu \mathrm{m}^{2}$ in the tamoxifen arm (Figure 2G). Thus, Usp28 inactivation significantly reduces both the number and the size of LSCC tumors.

23 To get insights into LSCC tumor regression, we focused on Usp28 substrates. 24 Immunoblotting analysis revealed that Usp28 deletion resulted in apoptotic cell death 25 (cleaved caspase-3; CC3). $\Delta$ p63 protein levels were reduced, but c-Jun and c-Myc 
1 protein became undetectable (Figure 2H, S3E). Usp28 deletion also decreased c-Jun

2 and c-Myc levels in KFCU LADC lesions, although the reduction in c-Myc protein levels

3 were significantly less pronounced than observed in LSCC (Figure 2E). Strikingly,

4 elimination of Usp28 has little effect, if any, on apoptotic cell death, as determined by

5 its inability to induce cleaved caspase-3 in LADC lesions. Thus, these data suggest

6 that Usp28 and its substrates are required for the maintenance of LSCC tumors.

7 To further investigate the role of Usp28 in LADC, we studied the consequences of

8 Usp28 deletion in a second LADC genetic model. We used Flp-inducible oncogenic

9 K-Ras activation combined with p53 deletion (FSF-KRas ${ }^{\mathrm{G} 12 \mathrm{D}}$ and $\operatorname{Trp53}^{\mathrm{FRT} / \mathrm{FRT}}$ or KP-

10 Flp model) (Schonhuber et al., 2014). The KP-Flp mice were crossed to a conditional

11 Usp28 flox/flox strain together with an inducible Cre ${ }^{\text {ERT }}$ recombinase knocked in at the

12 ROSA26 locus and an $\mathrm{mT} / \mathrm{mG}$ reporter allele (KPCU mice; Figure 3A). After

13 intratracheal adeno-CMV-FIp virus instillation, Usp28 was deleted in KPCU animals

14 displaying lung tumors by CT (Figure 3A). Loss of Usp28 expression in this second

15 LADC model also did not result in a reduction of LADC tumor number and size (Figure

16 3C, 3D). Successful Cre ${ }^{\text {ERT }}$ recombination was verified using lineage tracing (GFP staining) and deletion of Usp28 flox/flox alleles was further confirmed by BaseScope assays (Figure 3B, 3E). Therefore, also these data argue against an important role for Usp28 in LADC tumors.

Generation of a new USP28 inhibitor: selectivity and cellular target engagement The finding that Usp28 plays a key role in LSCC tumor maintenance prompted us to identify small molecule inhibitors against this deubiquitinase. A small molecule discovery campaign based on the ubiquitin-rhodamine cleavable assay (Turnbull et al., 2017) yielded a panel of compounds sharing a thienopyridine carboxamide 
1 chemical scaffold with inhibitory selectivity for USP28 and USP25 (Guerin, 2017;

2 Guerin et al., 2020; Zablocki et al., 2019). The compound FT206 (Figure 4A)

3 represents a different chemical class from the benzylic amino ethanol-based inhibitors

4 described previously (Wrigley et al., 2017). Quantitative structure-activity relationship

5 (SAR) was used to develop compound derivative FT206 that was most optimal in

6 terms of drug metabolism and pharmacokinetic properties (DMPK) while preserving

7 potency and selectivity towards USP28/25 (Zablocki et al., 2019). To confirm FT206

8 cellular target engagement, we used a Ub activity-based probe assay (ABP) (Altun et

9 al., 2011; Clancy et al., 2021; Panyain et al., 2020; Turnbull et al., 2017). ABPs can

10 assess DUB enzyme activity in a cellular context. DUB inhibition leads to displacement

11 of the ABP probe, resulting in a molecular weight shift measurable by SDS-PAGE and

12 immunoblotting against USP28/25. Using this approach, we found that the compound

13 FT206 interferes with USP28/25 probe labelling (USP-ABP versus USP) in LSCC

$14 \mathrm{H} 520$ cell extracts $\left(\mathrm{EC}_{50} \sim 300-1000 \mathrm{nM}\right.$, Figure 4B) and intact cells $\left(\mathrm{EC}_{50} \sim 1-3 \mu \mathrm{M}\right.$,

15 Figure 4C). In contrast to FT206, AZ1, a different USP28 inhibitor (Wrigley et al., 2017), based on a benzylic amino ethanol scaffold, appeared to exert lower potency towards USP28 $\left(\mathrm{EC}_{50}>30 \mu \mathrm{M}\right)$ and selectivity for USP25 $\left(\mathrm{EC}_{50} \sim 10-30 \mu \mathrm{M}\right)$ (Figure

S4A). To address compound selectivity more widely, we combined the ABP assay with quantitative mass spectrometry (ABPP) to allow the analysis of the cellular active DUBome (Benns et al., 2021; Jones et al., 2021; Pinto-Fernandez et al., 2019). When performing such assay in human LSCC cells, we were able to profile 28 endogenous DUBs, revealing a remarkable USP28/25 selectivity for FT206 in a dose-dependent manner (Figure 4D).

24 To further evaluate the efficacy of FT206 in targeting USP28, we tested its ability to modulate the ubiquitination status of endogenous USP28 substrates. The 
1 ubiquitination levels of c-Myc and c-Jun increased upon FT206 and MG132 co-

2 treatment (Figure 4SB), confirming that FT206 blocks USP28-mediated

3 deubiquitination of its substrates. The ubiquitination level of USP28 also increased

4 upon FT206 treatment (Figure 4SB), which is consistent with previous observations

5 where the enzymatic activity of DUBs can function to enhance their own stability (de

6 Bie and Ciechanover, 2011). Consequently, treatment of LSCC tumor cells with FT206

7 resulted in reduced c-Myc, C-Jun, $\Delta$ p63 and Usp28 protein levels, which were restored

8 upon addition of MG132 (Figure 4E, S4C).

9 Finally, FT206 treatment impaired LSCC cell growth (Figure 4F). However, in a 10 USP28-depleted background, FT206 neither affected cell growth nor reduced c-Myc 11 protein levels (Figure S4D). Thus, this data suggests that the effects of FT206 are mediated by USP28.

Pharmacological inhibition of USP28 is well tolerated in mice and induced LSCC tumor regression

We next evaluated the therapeutic potential of the USP28 inhibitor FT206 using the LSL-KRas ${ }^{\text {G12D; }}$ Fbxw7 flox/flox model (KF mice), which develop both LADC and LSCC tumor types (Ruiz et al., 2019). Nine weeks after adeno-CMV-Cre virus infection, when mice had developed lung tumors, we started treatment with USP28 inhibitor at 75 $\mathrm{mg} / \mathrm{kg}, 3$ times a week for 5 weeks (Figure 5A). FT206 administration had no noticeable adverse effects and treated mice maintained normal body weight (Figure S5A, S5B). Consistent with the effects observed by genetic Usp28 inactivation (Figure 2C), the number of KF LADC lesions was not affected by Usp28 inhibition via FT206 treatment (Figure 5B, 5C, 5D). By contrast, we found that FT206 effectively reduced LSCC tumor number by $68 \%$ (31 to 10 LSCC tumors, Figure $5 \mathbf{B}, \mathbf{5 E}$ ). 
1 Moreover, measurement of 252 individual KF LSCC mutant tumors (156 vehicle-

2 treated and 96 FT206-treated lesions) showed a significant reduction of over $45 \%$ in

3 tumor size upon FT206 treatment: an average of $8.5 \times 10^{4} \mu \mathrm{m}^{2}$ in the vehicle arm versus

$4 \quad 4.5 \times 10^{4} \mu \mathrm{m}^{2}$ in the FT206 cohort (Figure 5F). Thus, Usp28 inhibition by FT206 leads

5 to a dramatic reduction in the numbers of advanced LSCC tumors, and the small

6 number of remaining LSCC lesions are significantly reduced in size, resulting in a

7 reduction of total LSCC burden of over $85 \%$ by single agent treatment.

8 In line with the effects found by genetic Usp28 deletion, treatment of KF mice with

9 FT206 also resulted in reduced $\Delta$ p63, c-Jun and c-Myc protein levels (Figure 5G).

10 Consequently, FT206 treatment led to a substantial increase in the number of cleaved

11 caspase-3-positive cells in LSCC while LADC cells were not significantly affected,

12 indicating that Usp28 inhibition causes apoptotic cell death of LSCC tumor cells

13 (Figure 5H, 5I).

14 Finally, to further confirm the specificity of FT206, KFCU mice pre-exposed to tamoxifen to delete the conditional Usp28 floxed alleles were further treated with the USP28 inhibitor FT206. In this setting, Usp28 inhibition did not result in a further reduction of LADC and LSCC lesions (Figure 2C, 2F), suggesting that FT206 targets specifically Usp28.

USP28 inhibition causes dramatic regression of human LSCC xenograft tumors

21 To determine whether the promise of USP28 as a target in mouse lung cancer models 22 can be translated to a human scenario, we established human xenograft tumor 23 models. siRNA-mediated USP28 depletion, and USP28 inhibitor treatment, considerably reduced protein levels of $\Delta \mathrm{p} 63$, c-Jun and c-Myc and impaired growth in human LSCC tumor cells (Figure 6A-C, S6A). In contrast, FT206 treatment had 
1 marginal effects on c-Myc and c-Jun protein levels in human LADC cells (Figure S6B).

2 Crucially, FT206 led to a remarkable growth impairment of xenografts derived from

3 three independent human LSCC cell lines (Figure 6D-I), which was accompanied with

4 a strong reduction of c-Myc protein levels (Figure $6 \mathbf{J}-\mathbf{L}$ ). In summary, these data

5 suggest that USP28 pharmacological intervention is a promising therapeutic option for

6 human LSCC patients. 


\section{Discussion}

2 Unlike for LADC, there are few approved targeted therapies against LSCC.

3 Consequently, despite its limited effectiveness on disease progression and prognosis,

4 patients with LSCC receive the same conventional platinum-based chemotherapy

5 today as they would have received two decades ago (Fennell et al., 2016; Gandara et

$6 \quad$ al., 2015; Isaka et al., 2017; Liao et al., 2012; Scagliotti et al., 2008).

7 c-MYC is a transcription factor that orchestrates a potent pro-cancer programme

8 across multiple cellular pathways. As c-MYC is often overexpressed in late-stage

9 cancer, targeting it for degradation is an attractive strategy in many settings. The term

10 'undruggable' was coined to describe proteins that could not be targeted pharmacologically. Many desirable targets in cancer fall into this category, including the c-MYC oncoprotein, and pharmacologically targeting these intractable proteins is a key challenge in cancer research.

The deubiquitylase family of enzymes have emerged as attractive drug targets, that can offer a means to destabilize client proteins that might otherwise be undruggable (Schauer et al., 2019). The deubiquitinase USP28 was known to remove FBW7mediated ubiquitination of, and thereby stabilise, the oncoprotein c-MYC (Popov et al., 2007). Importantly, mice lacking Usp28 are healthy (Knobel et al., 2014), suggesting that Usp28 is dispensable for normal physiology and homeostasis.

In the current study we identified a requirement for USP28 for the maintenance of murine and human LSCC tumors. In agreement with the absence of major phenotypes in the Usp28 knock out mice, USP28 inhibitor treatment was well tolerated by the experimental animals, while having a dramatic effect on LSCC regression. USP28 small molecule inhibition phenocopies the effects of Usp28 deletion in LSCC regression, consistent with on-target activity. However, we cannot exclude that the 
1 inhibition of USP25 and possibly additional off-targets effects may contribute to the

2 observed phenotype. Inhibitor treated mice kept a normal body weight, indicating no

3 global adverse effects (Figure S5A).

4 While USP28 inhibition resulted in profoundly reduced LSCC growth, the effect on

5 LADC was modest. TP63, c-Jun and c-Myc protein levels are increased in LSCC

6 compared to LADC (Figure 1C, 1D). This could indicate a greater dependence of

7 LSCC on these oncoproteins, which consequently may result in increased sensitivity

8 to USP28 inhibition. We previously found that Usp28 deficiency corrected the

9 accumulation of SCF (Fbw7) substrate proteins, including c-Jun and C-Myc, in Fbw7-

10 mutant cells (Diefenbacher et al., 2015). The frequent downregulation of FBXW7 in

11 human LSCC (Ruiz et al., 2019) (Figure S2B) may underlie the increased accumulation of SCF(Fbw7) substrate proteins like c-Myc, c-Jun and p63 in LSCC, and thereby cause LSCC tumors to be increasingly dependent on USP28 function. Indeed, our study suggest that those 3 oncoproteins are all relevant targets of USP28 in LSCC (Figure 2H). In contrast, Prieto-Garcia et al. saw no difference in c-Jun and c-Myc protein levels, and suggested a different mechanism of action. Of note, our and the Prieto-Garcia et al. studies used different dual specificity inhibitors of USP28/25 that have distinct properties. FT206, the compound used in this study, preferentially inhibits USP28 compared to USP25, whereas AZ1, the compound used by PrietoGarcia et al. showed a pronounced activity towards USP25. In addition, FT206 inhibits USP28 in the nano-molar range, while Prieto-Garcia et al. typically used AZ1 at 10$30 \mu \mathrm{M}$, possibly because higher compound concentrations are required for therapeutic inhibition of USP28. Therefore differences in the selectivity and potency of the compounds used may explain some of the differences observed. 
1 Interestingly, all human LSCC cell lines used in the xenograft experiment (Figure 6),

2 each of which responded well to USP28 inhibition, do not show neither gain- or loss-

3 of-function mutations in USP28 nor FBXW7, respectively. Thus, these data support

4 the notion that LSCC tumor cells respond to USP28 inhibition, regardless of

5 USP28/FBXW7 mutation status, which suggest that USP28 inhibition might be a

6 therapeutic option for many LSCC patients.

7 In summary, our studies demonstrate that USP28 is a key mediator of LSCC

8 maintenance and progression and hence USP28 represents an exciting therapeutic

9 target. Therefore, USP28 inhibition should be considered as a potential therapy for

10 human lung squamous cell carcinoma. 


\section{Methods and Materials}

2

Mice

4 The LSL-KRas ${ }^{\text {G12D }}$ (Jackson et al., 2001), Fbxw7 floxflox (Jandke et al., 2011),

5 Usp28 $8^{\text {flox/flox }}$ (Diefenbacher et al., 2014), FSF-KRas ${ }^{\mathrm{G} 12 \mathrm{D}}$ (Schonhuber et al., 2014),

6 Trp53FRT/FRT (Schonhuber et al., 2014), ROSA26-FSF-Cre ${ }^{\text {ERT }}$ (Schonhuber et al.,

7 2014), ROSA26-LSL-mTmG (Muzumdar et al., 2007) strains have been previously

8 described. Immunocompromised NSG mice were maintained in-house. All animal

9 experiments were approved by the Francis Crick Institute Animal Ethics Committee

10 and conformed to UK Home Office regulations under the Animals (Scientific

11 Procedures) Act 1986 including Amendment Regulations 2012. All strains were

12 genotyped by Transnetyx. Each group contained at least 3 mice, which generates enough power to pick up statistically significant differences between treatments, as determined from previous experience (Ruiz et al., 2019). Mice were assigned to random groups before treatment.

\section{Generation of Fbxw7FRT/FRT Mice}

18 To generate a conditional allele of Fbxw7, we employed the CRISPR-Cas9 approach to insert two FRT sites into the intron 4 and 5 of Fbxw7, respectively. Two guide RNAs targeting the integration sites (gRNA-Int5A: accgtcggcacactggtcca; gRNA-Int4A: cactcgtcactgacatcgat), two homology templates containing the FRT sequences (gRNA-Int5B: agcactgacgagtgaggcgg; gRNA-Int4B: tgcctagccttttacaagat) and the Cas9 protein were micro-injected into the fertilised mouse eggs. The offspring were screened by PCR and one line with proper integration of two FRT sites was identified. 


\section{Analysis of public data from cancer genomics studies}

2 Data from TCGA Research Network (Lung Squamous Cell Carcinoma (TCGA,

3 Firehose Legacy)), including mutations, putative copy-number alterations, and mRNA

4 Expression (mRNA expression z-scores relative to diploid samples (RNA Seq V2

5 RSEM; threshold 2.0), were analyzed using cBioportal software and visualized using

6 the standard Oncoprint output (Cerami et al., 2012). The Onco Query Language (OQL)

7 used was "USP28: MUT AMP GAIN EXP >= 2" "FBXW7: MUT HOMDEL

8 HETLOSS EXP <= -2". Source data was from GDAC Firehose, previously known as

9 TCGA Provisional. The complete sample set used was $(n=178)$. Expression analysis 10 was performed using GEPIA (Gene expression profiling interactive analysis) software 11 (2017).

\section{Human lung tumor analysis}

14 Human biological samples were collected, stored, and managed by the Cordoba node belonging to the Biobank of the Andalusian Health Service (Servicio Andaluz de SaludSAS) and approved by the Ethics and Clinical Research Committee of the University

17 Hospital Reina Sofia. All subjects gave informed consent. Pathologists assessed all samples before use. mRNA extracted from the samples was analyzed by qPCR. Primers are listed in Table 1.

\section{Tumor induction and tamoxifen treatment}

22 Induction of NSCLC tumors was carried out in anesthetized (2-2.5\% isoflurane) mice by intratracheal instillation of a single dose of $2.5 \times 10^{7}$ pfu of adenoviruses encoding 24 either the Cre recombinase (adeno-CMV-Cre) or Flp recombinase (adeno-CMV-FIp). 


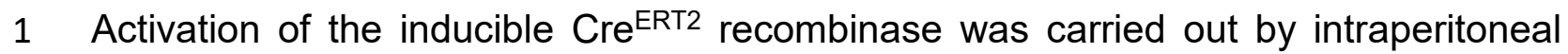

2 injection of tamoxifen (100 $\mu \mathrm{g} / \mathrm{kg}$ body weight) dissolved in peanut oil for 10 days.

3

\section{$4 \quad$ CT image acquisition and processing}

5 The SkyScan-1176, a high-resolution low-dose X-ray scanner, was used for 3D

\section{Mouse treatments with FT206}

Nine-weeks upon Ad5-CMV-Cre infection, LSL-KRas ${ }^{\text {G12D; Fbxw7 }} 7^{\text {flox/flox }}$ mice were treated with FT206 (75 mg/kg) via oral gavage on day 1, 3, and 5 per week during 5 weeks. Body weights were register every week.

\section{In vivo pharmacology with subcutaneous graft tumors}

Human LSCC tumor cell lines (NCI-H520, CALU-1 and LUDLU-1) were resuspended as single-cell suspensions at $10^{7}$ cells/ml in PBS:Matrigel. $100 \mu \mathrm{l}\left(10^{6}\right.$ cells total) of this suspension was injected into the flanks of immunodeficient NSG mice. When tumors were palpable, treatment with FT206 $(75 \mathrm{mg} / \mathrm{kg})$ was initiated with the same schedule on day 1,3 , and 5 per week. Tumor grafts were measured with digital callipers, and tumor volumes were determined with the following formula: (length $\times$ width $\left.^{2}\right) \times(\pi / 6)$. Tumor volumes are plotted as means \pm SD. 


\section{Histopathology, Immunohistochemistry and BaseScope analysis}

2 For histological analysis, lungs were fixed overnight in $10 \%$ neutral buffered formalin.

3 Fixed tissues were subsequently dehydrated and embedded in paraffin, and sections

$4(4 \mu \mathrm{m})$ were prepared for H\&E staining or IHC. Antibodies are given in Table 2.

5 BaseScope was performed following the manufacturer's protocol. The Usp28-specific

6 probe was custom-designed to target 436-482 of NM_175482.3; Ppib probe was used

7 as a positive control (Bio-Techne Ltd).

8 Tumor numbers were counted from whole lung sections: LADC and LSCC tumors

9 were identified by Sftpc and CK5 stains, respectively. Tumor areas $\left(\mu \mathrm{m}^{2}\right)$ were measured from lung sections using Zen3.0 (blue edition) software. For quantification

11 of tumor cell death, the number of cleaved caspase-3-positive cells was counted in

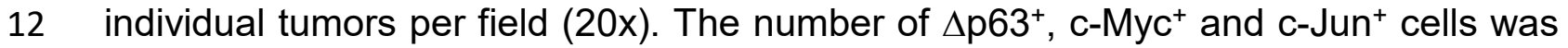
counted in individual tumors $/ 10,000 \mu \mathrm{m}^{2}$. All analyses were performed uniformity across all lung sections and the whole lungs were used to derive data.

Cell culture

17 Primary KF LSCC cells were cultured in N2B27 medium containing EGF (10 ng/ml; Pepro Tech) and FGF2 (20 ng/ml; Pepro Tech) (Ruiz et al., 2019). Human lung squamous cell carcinoma (NCl-H226, NCl-H520, CALU-1 and LUDLU-1) and lung adenocarcinoma $(\mathrm{NCl}-\mathrm{H} 23, \mathrm{NCl}-\mathrm{H} 441$ and $\mathrm{NCl}-\mathrm{H} 1650)$ lines were provided by the

21 Francis Crick Institute Cell Services and cultured in RPMI-1640 medium supplemented with 10\% FBS, 1\% penicillin/streptomycin, 2mM Glutamine, 1\% NEEA and $1 \mathrm{mM}$ Na Pyruvate. All cells were tested Mycoplasma negative and maintained at $37^{\circ} \mathrm{C}$ with $5 \% \mathrm{CO}_{2}$. 


\section{Cell treatments}

2 Mouse KF LSCC and human LUDLU-1 cells were treated with vehicle or FT206 at

3 different concentrations for $48 \mathrm{hr}$ to analyse c-Myc, c-Jun and $\Delta \mathrm{p} 63$ protein levels by

4 western-blotting.

5 Primary mouse KF LSCC cells were infected with inducible-shRNAs against the

6 Usp28 gene and then expose to Doxycycline hyclate $(1 \mu \mathrm{g} / \mathrm{ml})$ for $48 \mathrm{~h}$. Cell number

7 was counted using an automated cell counter (Thermo Fisher Scientific, Countess

8 Automated Cell Counter).

9 Mouse KF LSCC and human cell lines were transfected with specific small interfering 10 RNAs (siRNAs) against the MYC, JUN, TP63 or USP28 genes, using Lipofectamine

11 RNAiMAX and 25nM of each siRNA according to the manufacturer's instructions

12 (Dharmacon). 72-96h later, cell number was counted using an automated cell counter.

13 For IC50, mouse KF LSCC and human cells were treated with vehicle or FT206 at 14 different concentrations for $72 \mathrm{~h}$. Cell viability was measured as the intracellular ATP 15 content using the CellTiter-Glo Luminescent Cell Viability Assay (Promega), following the manufacturer's instructions. IC 50 was calculated using GraphPad Prism software.

\section{Western Blot Analysis}

19 Cells were lysed in ice-cold lysis buffer (20 mM Tris $\mathrm{HCl}, \mathrm{pH} 7.5,5 \mathrm{mM} \mathrm{MgCl}, 50 \mathrm{mM}$ $20 \mathrm{NaF}, 10 \mathrm{mM}$ EDTA, $0.5 \mathrm{M} \mathrm{NaCl}$, and $1 \%$ Triton $\mathrm{X}-100$ ) that was completed with protease, phosphatase, and kinase inhibitors. Protein extracts were separated on SDS/PAGE gel, transferred to a nitrocellulose membrane and blotted with antibodies are given in Table 2. Primary antibodies were detected against mouse or rabbit IgGs and visualized with ECL Western blot detection solution (GE Healthcare) or Odyssey infrared imaging system (LI-COR, Biosciences). 


\section{USP28 inhibitor synthesis}

2 Synthesis and characterization of the USP28/25 small molecule inhibitor FT206, a

3 thienopyridine carboxamide derivative, has been described previously in the patent 4 application WO 2017/139778 Al (Guerin, 2017) and more recent updates WO 5 2019/032863 (Zablocki et al., 2019) and WO 2020/033707 (Guerin et al., 2020), where

6 FT206 is explicitly disclosed as Example 11.1.

7

\section{Cellular DUB profiling using Ub-based active site directed probes}

Molecular probes based on the ubiquitin scaffold were generated and used essentially as described (Pinto-Fernandez et al., 2019; Turnbull et al., 2017). In brief, HA-tagged

Ub propargyl probes were synthesised by expressing the fusion protein HA-Ub75Intein-Chitin binding domain in E.Coli BL21 strains. Bacterial lysates were prepared and the fusion protein purified over a chitin binding column (NEB labs, UK). HA-Ub75thioester was obtained by incubating the column material with mercaptosulfonate sodium salt (MESNa) overnight at $37^{\circ} \mathrm{C}$. HA-Ub75-thioester was concentrated to a concentration of $\sim 1 \mathrm{mg} / \mathrm{ml}$ using 3,000 MW filters (Sartorius) and then desalted against

17 PBS using a PD10 column (GE Healthcare). $500 \mu \mathrm{L}$ of $1-2 \mathrm{mg} / \mathrm{mL}$ of HA-Ub75thioester was incubated with $0.2 \mathrm{mmol}$ of bromo-ethylamine at $\mathrm{pH} 8-9$ for 20 minutes at ambient temperature, followed by a desalting step against phosphate buffer $\mathrm{pH} 8$ as described above. Ub probe material was concentrated to $\sim 1 \mathrm{mg} / \mathrm{ml}$, using 3,000 MW filters (Sartorius), and kept as aliquots at $-80^{\circ} \mathrm{C}$ until use.

DUB profiling competition assays with cell extracts and with cells

Crude $\mathrm{NCl}-\mathrm{H} 520$ cell extracts were prepared as described previously using glassbead lysis in $50 \mathrm{mM}$ Tris $\mathrm{pH}$ 7.4, $5 \mathrm{mM} \mathrm{MgCl}_{2}, 0.5 \mathrm{mM}$ EDTA, $250 \mathrm{mM}$ sucrose, $1 \mathrm{mM}$ 
1 DTT. For experiments with crude cell extracts, $50 \mu \mathrm{g}$ of $\mathrm{NCl}-\mathrm{H} 520$ cell lysate was

2 incubated with different concentrations of USP28 inhibitor compounds (FT206 and

3 AZ1) for one hour at $37^{\circ} \mathrm{C}$, followed by addition of $1 \mu \mathrm{g} \mathrm{HA}-\mathrm{UbPA}$ and incubation for

410 minutes (Figure 4B, 4C) or 30 minutes (Figure S4A comparing FT206 and AZ1) at

$537^{\circ} \mathrm{C}$. Incubation with Ub-probe was optimised to minimise replacement of non-

6 covalent inhibitor FT206 by the covalent probe. Samples were then subsequently

7 boiled in reducing SDS-sample buffer, separated by SDS-PAGE and analysed by

8 Western Blotting using anti-HA (Roche, 1:2000), anti-USP28 (Abcam, 1:1000), anti-

9 USP25 (Abcam, 1:1000), anti-GAPDH (Invitrogen, 1:1000) or beta Actin (Abcam,

10 1:2000) antibodies. For cell-based DUB profiling, $5 \times 10^{6}$ intact cells were incubated

11 with different concentrations of inhibitors in cultured medium for 4 hours at $37{ }^{\circ} \mathrm{C}$,

12 followed by glass-bead lysis, labelling with HA-UbPA probe, separation by SDS-PAGE and Western blotting as described above.

\section{DUB inhibitor profiling by quantitative mass spectrometry}

Ub-probe pulldown experiments in presence of different concentrations of the inhibitor

17 FT206 were performed essentially as described (Pinto-Fernandez et al., 2019;

Turnbull et al., 2017) with some modifications. In brief, immune precipitated material from $500 \mu \mathrm{g}-1 \mathrm{mg}$ of $\mathrm{NCl}-\mathrm{H} 520$ cell crude extract was subjected to in-solution trypsin digestion and desalted using C18 SepPak cartridges (Waters) based on the manufacturer's instructions. Digested samples were analyzed by nano-UPLC-MS/MS using a Dionex Ultimate 3000 nano UPLC with EASY spray column $(75 \mu \mathrm{m} \times 500 \mathrm{~mm}$, 
1 Q Exactive High Field (HF) instrument in which survey scans were acquired at a

2 resolution of 60.000 at $400 \mathrm{~m} / \mathrm{z}$ and the 20 most abundant precursors were selected

3 for CID fragmentation. From raw MS files, peak list files were generated with

4 MSConvert (Proteowizard V3.0.5211) using the 200 most abundant peaks/spectrum.

5 The Mascot (V2.3, Matrix Science) search engine was used for protein identification

6 at a false discovery rate of $1 \%$, mass deviation of $10 \mathrm{ppm}$ for MS1 and $0.06 \mathrm{Da}(\mathrm{Q}$

7 Exactive HF) for MS2 spectra, cys carbamidylation as fixed modification, met oxidation

8 and Gln deamidation as variable modification. Searches were performed against the

$9 \quad$ UniProtKB human sequence data base (retrieved 15.10.2014). Label-free quantitation

10 was performed using MaxQuant Software (version 1.5.3.8), and data further analysed

11 using GraphPad Prism software (v7) and Microsoft Excel. Statistical test-s ANOVA

12 (multiple comparison; Original FDR method of Benjamini and Hochberg) was

13 performed using GraphPad Prism software. The MS data was submitted to PRIDE for

14 public repository with an internal ID of px-submission \#469830.

TUBE pulldown

17 Endogenous poly-Ub conjugates were purified from cells using TUBE affinity reagents 18 (LifeSensors, UM401). Cells were lysed in buffer containing $50 \mathrm{mM}$ Tris- $\mathrm{HCl} \mathrm{pH}$ 7.5, $190.15 \mathrm{M} \mathrm{NaCl}, 1 \mathrm{mM}$ EDTA, 1\% NP-40, 10\% glycerol supplemented with complete 20 protease inhibitor cocktail, PR-619 and 1,10-phenanthroline. Lysate was cleared by 21 centrifugation, Agarose-TUBEs were added, and pulldown was performed for $16 \mathrm{~h}$ at $4{ }^{\circ} \mathrm{C}$ on rotation. The beads were then washed three times with $1 \mathrm{ml}$ of ice-cold TBS-

$23 \mathrm{~T}$, and bound material was eluted by mixing the beads with sample buffer and heating 24 to $95^{\circ} \mathrm{C}$ for $5 \mathrm{~min}$. 


\section{Statistical analysis}

2 Data are represented as mean \pm S.E.M.. Statistical significance was calculated with

3 the unpaired two-tailed Student's t test, one-way or two-way analysis of variance

4 (ANOVA) followed by multiple comparison test using GraphPad Prism software. A $P$

5 value that was less than 0.05 was considered to be statistically significant for all data

6 sets. Significant differences between experimental groups were: ${ }^{*} p<0.05,{ }^{* *} p<0.01$

7 or ${ }^{* * *} p<0.001$. Biological replicates represent experiments performed on samples

8 from separate biological preparations; technical replicates represent samples from the

9 same biological preparation run in parallel. 


\section{Acknowledgements}

2 Part of this work was funded by Forma Therapeutics. This work was also supported

3 by the Francis Crick Institute which receives its core funding from Cancer Research

4 UK (FC001039), the UK Medical Research Council (FC001039), and the Wellcome

5 Trust (FC001039). We thank the Discovery Proteomics Facility (led by Dr Roman

6 Fischer) at the Target Discovery Institute (Oxford) for expert help with the analysis by

7 mass spectrometry. Work in the B.M.K. laboratory was supported by a John Fell

8 Fund 133/075, the Wellcome Trust (097813/Z/11/Z) and the Engineering and

9 Physical Sciences Research Council (EP/N034295/1).

\section{Author Contributions}

12 EJR, CJD, TRH, SK, DK, NJ, MW, SU, MJC, BMK and AB designed the study. EJR, LL, EMR, CDC, IR, NM and EN performed mouse genetics and in vivo experiments. EJR, TMC, AD, GV, HCS, CH and APF performed biochemical experiments with the help of APT, WWK, MG, DK and BMK. DG, JK, MK, CM, SI, JCC and CJD designed and characterised small molecule inhibitors. All authors commented on the manuscript. EJR, APF, BMK and AB wrote the manuscript.

\section{Declaration of Interests}

None of the authors from pharmaceutical companies declare competing financial

21 interests with their current affiliations. The authors APT, WWK, DG, JK, SI, MK, CK, $22 \mathrm{JOC}, \mathrm{NJ}, \mathrm{CH}, \mathrm{TRH}, \mathrm{DK}, \mathrm{SK}, \mathrm{SU}, \mathrm{MJC}, \mathrm{BMK}$ an $\mathrm{AB}$ declare competing financial 23 interests due to financial support for the project described in this manuscript by Forma 24 Therapeutics, Watertown, MA, USA. 


\section{Figure legends}

2 Figure 1. MYC, JUN and $\triangle \mathrm{p} 63$ are highly expressed in LSCC tumors

A) Expression of MYC in human lung adenocarcinoma ( $L A D C, n=483$ ), lung squamous cell carcinoma (LSCC, $\mathrm{n}=486$ ), and normal non-transformed tissue (normal LSCC $=338$, normal LADC $=347$ ). In box plots, the centre line reflects the median. Data from TCGA and GTEx were analyzed using GEPIA software.

B) Relative mRNA expression of MYC in normal lung tissue $(n=5)$ and LSCC $(n=17)$ patient samples from the Cordoba Biobank measured by RT-PCR. The P value was calculated using the Student's two-tailed $t$ test. Plots indicate mean.

C) Representative LADC and LSCC tumors stained with c-Myc, C-Jun and $\Delta$ p63 antibodies. Scale bars, $30 \mu \mathrm{m}$.

D) Quantification of c-Myc ${ }^{+}(\operatorname{LADC} n=33, \operatorname{LSCC} n=34), c-J u n^{+}(\operatorname{LADC} n=33$, LSCC $\mathrm{n}=33)$ and $\triangle \mathrm{p} 63^{+}$cells (LADC $\left.\mathrm{n}=41, \mathrm{LSCC} \mathrm{n}=41\right)$ in LADC and LSCC tumors. Plots indicate mean. Student's two-tailed $t$ test was used to calculate $P$ values.

E) Graph showing the difference in cell proliferation between control and MYCdepleted KF LSCC cells $(n=3)$. Graph indicates mean \pm S.E.M.. Student's two-tailed $t$ test was used to calculate $P$ values.

F) Genetic alterations in USP28 and FBXW7 genes in human LSCC. Each column represents a tumor sample $(n=178)$. Data from TCGA were analyzed using cBioportal software.

G) Relative mRNA expression of USP28 in normal lung tissue $(n=5)$ and LSCC ( $n=$ 17) patient samples from the Cordoba Biobank measured by RT-PCR. The P value was calculated using the Student's two-tailed t test. Plots indicate mean. See also Supplementary Figure S2B. 
1 H) shRNA-mediated knockdown of Usp28 decreases c-Myc, c-Jun and $\Delta$ p63 protein

2 levels in primary KF LSCC cells.

3 I) Graph showing the difference in cell proliferation between control and Usp28-

4 depleted KF LSCC cells $(n=3)$. Graph indicates mean \pm S.E.M.. One-way ANOVA

5 with Dunnett's multiple comparisons test was used to calculate $P$ values.

7 Figure 2. Usp28 is an effective therapeutic target for LSCC tumors

8 A) Schematic representation of the KFCU (FSF-ras ${ }^{\mathrm{G} 12 \mathrm{D}}$; Fbxw7 ${ }^{\text {FRT/FRT; }}$ ROSA26-

9 FSF-Cre ${ }^{\mathrm{ERT}}$; Usp28 $8^{\text {flox/flox }}$ ) model and experimental approach used to deplete conditional Usp28 alleles in established lung tumors.

11 B) Lung histology of animals treated as in A, showing both LSCC $\left(\mathrm{CK}^{+}\right)$and LADC $12\left(\mathrm{Sftpc}^{+}\right)$tumors in mice receiving vehicle but few LSCC lesions in mice receiving 13 tamoxifen. Scale bars, $1000 \mu \mathrm{m}$.

14 C) Quantification of LADC tumors in vehicle-, tamoxifen- and tamoxifen+FT206 treated KFCU mice. Plots indicate mean. One-way ANOVA with Tukey's multiple 'comparisons test was used to calculate $P$ values $(n=8$ vehicle, $n=7$ tamoxifen, $n=$

177 tamoxifen + FT206).

D) Quantification of LADC tumor size in vehicle-, tamoxifen- and tamoxifen+FT206

19 treated KFCU mice. Plots indicate mean. One-way ANOVA with Tukey's multiple 20 'comparisons test was used to calculate $P$ values $(n=466$ vehicle, $n=434$ tamoxifen, $21 \mathrm{n}=503$ tamoxifen + FT206).

22 E) Immunoblot analysis of LADC tumors probed for Usp28, c-Myc, c-Jun, Sftpc, 23 cleaved caspase-3 (CC3). Vinculin is shown as loading control.

24 F) Quantification of LSCC tumors in vehicle-, tamoxifen- and tamoxifen+FT206 treated 25 KFCU mice. Plots indicate mean. One-way ANOVA with Tukey's multiple 
1 'comparisons test was used to calculate $P$ values $(n=8$ vehicle, $n=7$ tamoxifen, $n=$

27 tamoxifen + FT206).

3 G) Quantification of LSCC tumor size in vehicle-, tamoxifen- and tamoxifen+FT206

4 treated KFCU mice. Plots indicate mean. One-way ANOVA with Tukey's multiple

5 'comparisons test was used to calculate $P$ values $(n=326$ vehicle, $n=103$ tamoxifen,

$6 \mathrm{n}=79$ tamoxifen + FT206).

7 H) Usp28 deletion induces apoptotic cell death (cleaved caspase-3, CC3) and

8 decreases c-Myc, C-Jun and $\Delta$ p63 protein levels in LSCC lesions.

9

10 Figure 3. Usp28 is not a therapeutic target for advanced KRas ${ }^{\text {G12D; }}$ Trp53 mutant

11 tumors

12 A) Schematic representation of the KPCU (FSF-K KRas ${ }^{\text {G12D; }}$ p53 ${ }^{\text {FRT/FRT; }}$ ROSA26-FSF-

13 Cre ${ }^{\text {ERT; }}$ U Usp28 $8^{\text {flox/flox; }}$ ROSA26-LSL-mTmG) model and experimental approach used.

14 At 10-weeks post-infection, KPCU mice were treated with vehicle or tamoxifen.

15 B) Representative images of H\&E (left) and GFP (right) stains from mice of the 16 indicated treatments. Scale bar, $1000 \mu \mathrm{m}$.

17 C) Quantification of mouse LADC tumors in the KPCU model. Plots indicate mean.

18 Student's two-tailed t test was used to calculate $P$ values $(n=10$ vehicle, $n=10$ 19 tamoxifen).

20 D) Quantification of LADC tumor size in vehicle- and tamoxifen-treated KPCU mice.

21 Plots indicate mean. Student's two-tailed t test was used to calculate $P$ values $(n=$ 22110 vehicle, $\mathrm{n}=130$ tamoxifen).

23 E) Representative images illustrating histological analysis of lung lesions in KPCU 24 mice, treated with vehicle or tamoxifen. H\&E, Sftpc, TTF1, GFP immunohistochemistry 
1 staining and in situ hybridization of USP28 and PPIB mRNA expression. Scale bars,

$250 \mu \mathrm{m}$.

3

$4 \quad$ Figure 4. USP28 inhibitor selectivity and cellular target engagement

5 A) Structure of small molecular inhibitor FT3951206/CRT0511973 (FT206).

6 B) Cellular DUB profiling in NCl-H520 LSCC cell extracts incubated with the indicated

7 concentrations of FT206 prior to labelling with HA-UbPA, SDS-PAGE and analysis by

8 Western blotting. Inhibitor potency was reflected by competition with USP28/25-ABP

9 adduct formation.

10 C) Cellular DUB profiling in NCl-H520 LSCC cells incubated with the indicated 11 concentrations of FT206, lysed extracts labelled with HA-UbPA and analysed as in B.

12 D) Activity-based Probe Profiling (ABPP) demonstrating the cellular DUB selectivity 13 profile of cpd FT206 by quantitative mass spectrometry analysis at different inhibitor 14 concentrations. Graph indicates mean \pm S.E.M..

E) Usp28 inhibition using FT206 (50nM and 100nM) reduces c-Myc, c-Jun and $\Delta$ p63 protein levels in primary KF LSCC cells.

F) Usp28 inhibition using FT206 decreases cell proliferation in KF LSCC cells $(n=4)$.

18 Graph indicates mean \pm S.E.M..

Figure 5. Pharmacologic USP28 inhibition reduces c-Myc, C-Jun and $\Delta$ p63 protein levels in mouse LSCC tumors, and induces tumor cell death a week for 5 weeks. 
1 B) Lung histology of animals treated as in A, showing both LSCC $\left(\mathrm{CK} 5^{+}\right)$and LADC

$2\left(\mathrm{Sftpc}^{+}\right)$tumors in LSL-KRas ${ }^{\mathrm{G} 12 \mathrm{D}} ; \mathrm{Fbxw7}^{\mathrm{f} / \mathrm{f}}(\mathrm{KF})$ mice receiving vehicle but few LSCC

3 lesions in mice receiving FT206. Scale bars, $1000 \mu \mathrm{m}$.

4 C) Quantification of LADC tumors per animal in vehicle- and FT206-treated KF mice.

5 Plots indicate mean. $P$ values calculated using Student's two-tailed t test $(n=7$ vehicle, $6 \mathrm{n}=10$ FT206).

7 D) Quantification of LADC tumor size in vehicle- and FT206-treated KF mice. Plots

8 indicate mean. Student's two-tailed t test was used to calculate $P$ values $(n=304$

9 vehicle, $\mathrm{n}=481$ FT206).

10 E) Quantification of LSCC tumors per animal in vehicle- and FT206-treated KF mice.

11 Plots indicate mean. P values calculated using Student's two-tailed t test $(n=7$ vehicle, $12 \mathrm{n}=10 \mathrm{FT} 206)$.

13 F) Quantification of LSCC tumor size in vehicle- and FT206-treated KF mice. Plots 14 indicate mean. Student's two-tailed t test was used to calculate $P$ values $(n=156$ 15 vehicle, $\mathrm{n}=96$ FT206).

G) LSCC tumors stained with c-Myc, c-Jun and $\Delta$ p63 antibodies. KF animals treated with vehicle (left panel) or FT206 (right panel). Inserts showing c-Myc ${ }^{+}, \mathrm{c}-\mathrm{Jun}^{+}, \Delta \mathrm{p} 63^{+}$ 18 LSCC tumors in mice receiving vehicle (left panel) but partial positive or negative LSCC lesions in mice receiving FT206 (right panel). Scale bars, $50 \mu \mathrm{m}$.

H) Scheme depicting experimental design for in vivo test of FT206 (75 mg/kg) for 4

21 days consecutively (upper panel). Cleaved caspase-3 (CC3) stain shows apoptotic 22 cells (bottom panel). Scale bars, $50 \mu \mathrm{m}$.

23 I) Quantification of cleaved caspase-3 (CC3)-positive cells per field (20x) in LADC ( $\mathrm{n}$ $24=114$ vehicle, 203 FT206) and LSCC ( $\mathrm{n}=94$ vehicle, 167 FT206) tumors from KF 
1 mice treated as in $\mathrm{H}$. Plots indicate mean. Student's two-tailed $\mathrm{t}$ test was used to

2 calculate $\mathrm{P}$ values.

3 See also Supplementary Figure S5.

4

5 Figure 6. Pharmacological inhibition of USP28 prevents human LSCC tumor

6 progression and reduces c-Myc protein levels in xenograft models

7 A) siRNA-mediated knockdown of USP28 decreases c-Myc, c-Jun and $\Delta$ p63 protein

8 levels in human LUDLU-1 LSCC cells.

9 B) USP28 inhibition using FT206 (0.2 and $0.4 \mu \mathrm{M})$ reduces c-Myc, c-Jun and $\Delta$ p63 protein levels in human LUDLU-1 LSCC cells.

C) USP28 inhibition using FT206 decreases cell proliferation in human LSCC (NCIH520, CALU-1 and LUDLU-1) cell lines $(n=8)$. Graphs indicate mean \pm S.E.M..

D, E, F) In vivo tumor graft growth curves of human LSCC (NCI-H520, CALU-1 and LUDLU-1) cell lines subcutaneously injected in flanks of immunocompromised mice. Animals with palpable tumors were treated with vehicle or FT206 $(75 \mathrm{mg} / \mathrm{kg})$ via oral gavage. Plots indicate mean \pm SD of the tumor volumes. P values calculated from twoway ANOVA with Bonferroni's multiple comparisons test $(\mathrm{NCl}-\mathrm{H} 520 \mathrm{n}=4$ vehicle and 4 FT206; CALU-1 n = 3 vehicle and 3 FT206; LUDLU-1 n = 3 vehicle and 3 FT206). xenograft tumors at the end point. Student's two-tailed t test was used to calculate P values $(\mathrm{NCl}-\mathrm{H} 520 \mathrm{n}=4$ vehicle and 4 FT206; CALU-1 $\mathrm{n}=3$ vehicle and 3 FT206; LUDLU-1 $\mathrm{n}=3$ vehicle and 3 FT206). 


\section{Supplementary figure legends}

\section{Supplementary Figure S1, related to Figure 1.}

3 A) Graphs showing the difference in cell proliferation between control and siMYC-

4 transfected human LSCC cell lines (NCl-H226, NCI-H520, CALU-1 and LUDLU-1).

5 Graphs indicate mean \pm S.E.M.. P values calculated using one-way ANOVA with

6 Tukey's multiple comparisons test.

7 B) Graphs showing the difference in cell proliferation between control and siJUN-

8 transfected human LSCC cell lines (NCI-H226, NCI-H520, CALU-1 and LUDLU-1).

9 Graphs indicate mean \pm S.E.M.. P values calculated using one-way ANOVA with

10 Tukey's multiple comparisons test.

11 C) Graphs showing the difference in cell proliferation between control and si $\Delta$ Np63transfected human LSCC cell lines (NCI-H226, NCI-H520, CALU-1 and LUDLU-1).

13 Graphs indicate mean \pm S.E.M.. P values calculated using one-way ANOVA with 14 Tukey's multiple comparisons test.

\section{Supplementary Figure S2, related to Figure 1.}

A) Dot plot showing association between the $\log _{2}$ mRNA expression (Y-axis) and copynumber alterations (X-axis) for USP28 gene. Data from TCGA were analyzed using cBioportal software. One-way ANOVA with Bonferroni's multiple comparisons test was used to calculate $P$ values $(n=2$ Deep deletion, $n=57$ Shallow deletion, $n=81$ Diploid, $\mathrm{n}=38$ Gain).

B) Representative human LSCC tumors stained with USP28 and FBW7 antibodies. in LSCC tumors $(n=17)$ (right panel). 
1 Supplementary Figure S3, related to Figure 2. Gene targeting strategy to

2 generate a Fbxw7 FRT/FRT allele that can be deleted by Flp recombinase.

3 A) Gene targeting strategy to generate conditional Fbxw7 $7^{\mathrm{FRT} / F R T}$ animals. Two FRT

4 sites were inserted into the intron 4 and 5 of Fbxw7 through the CRISPR-Cas9

5 technology.

6 B) Schematic representation of the conditional allele (left panel). In vitro recombination

7 assay demonstrated efficient ablation of the exon 5 upon Flp recombinase adenovirus

8 infection (right panel).

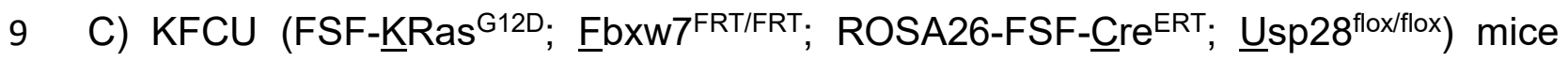
10 infected with adeno-CMV-FIp virus develop LADC $\left(\mathrm{Sftpc}^{+}\right.$and $\left.\mathrm{TTF}^{+}\right)$and $\mathrm{LSCC}$ $11\left(\mathrm{CK}^{+}\right.$and $\left.\Delta \mathrm{p} 63^{+}\right)$tumors.

D) In situ hybridization of USP28 and PPIB mRNA expression in vehicle- and tamoxifen-treated KFCU mice. Scale bars, $50 \mu \mathrm{m}$.

E) KFCU tumors stained with c-Myc, c-Jun and $\Delta$ p63 antibodies. KFCU mice treated with vehicle (left panel) or tamoxifen (right panel). Inserts showing c-Myc+, c-Jun+ and $\triangle \mathrm{p} 63+\mathrm{LSCC}$ tumors in mice receiving vehicle but partial positive or negative LSCC lesions in mice receiving tamoxifen. Scale bars, $50 \mu \mathrm{m}$.

Supplementary Figure S4, related to Figure 4.

A) Comparison of USP28/25 inhibitor potency by activity-based profiling. Human LSCC H520 crude cell extracts were incubated either with AZ1 or FT206 inhibitors at 22 indicated concentrations, followed by HA-UbPA activity-based probe (ABP) labelling. Samples were analysed by SDS-PAGE and immunoblotted using USP28, USP25, HA, and GAPDH antibodies. Inhibitor potency was reflected by competition with USP28/25-ABP adduct formation. 
1 B) TUBE pulldown of endogenous ubiquitylated c-Myc, c-Jun and USP28 in LSCC

2 cells upon co-treatment with MG132 and FT206.

3 C) Immunoblot of endogenous USP28, c-Jun, c-Myc and $\Delta$ p63 in LSCC cells upon co-

4 treatment with MG132 and FT206. Vinculin served as loading control.

5 D) Graphs showing the difference in cell proliferation between control, FT206-treated

6 and USP28-depleted LSCC cells. Graph indicates mean \pm S.E.M.. One-way ANOVA

7 with Tukey's multiple comparisons test was used to calculate $P$ values. Vinculin is

8 shown as loading control.

Supplementary Figure S5, related to Figure 5.

A) Monitoring tolerability in mice treated with FT206 $(75 \mathrm{mg} / \mathrm{kg}), 3$ times a week for 5 12 weeks. Body weights of animals during the course of treatment $(n=3$ vehicle, $n=3$ 13 FT206).

14 B) Kidney, liver and spleen sections stained with H\&E. Mice treated as in A. Bars, 100 $\mu \mathrm{m}$.

\section{Supplementary Figure S6, related to Figure 6.}

18 A) Immunoblot of endogenous c-Myc and c-Jun in LSCC cells upon FT206 treatment

19 (IC50 doses display in panel C). Vinculin served as loading control.

B) Immunoblot of endogenous c-Myc and c-Jun in LADC cells upon FT206 treatment

21 (IC50 doses display in panel C). Vinculin served as loading control.

C) IC50 values (doses that inhibits $50 \%$ of the cell viability) were calculated after exposure of human LADC and LSCC cells to different concentrations of FT206 compound. 


\section{References}

2

Altun, M., Kramer, H. B., Willems, L. I., McDermott, J. L., Leach, C. A., Goldenberg, S. J., Kumar, K. G., Konietzny, R., Fischer, R., Kogan, E., et al. (2011). Activity-based chemical proteomics accelerates inhibitor development for deubiquitylating enzymes. Chem Biol 18, 14011412.

Benns, H. J., Wincott, C. J., Tate, E. W., and Child, M. A. (2021). Activity- and reactivity-based proteomics: Recent technological advances and applications in drug discovery. Curr Opin Chem Biol 60, 20-29.

Cancer Genome Atlas Research, N. (2012). Comprehensive genomic characterization of squamous cell lung cancers. Nature $489,519-525$.

Cardarella, S., and Johnson, B. E. (2013). The impact of genomic changes on treatment of lung cancer. Am J Respir Crit Care Med 188, 770-775.

Cerami, E., Gao, J., Dogrusoz, U., Gross, B. E., Sumer, S. O., Aksoy, B. A., Jacobsen, A., Byrne, C. J., Heuer, M. L., Larsson, E., et al. (2012). The cBio cancer genomics portal: an open platform for exploring multidimensional cancer genomics data. Cancer Discov 2, 401-404.

Clancy, A., Heride, C., Pinto-Fernandez, A., Elcocks, H., Kallinos, A., Kayser-Bricker, K. J., Wang, W., Smith, V., Davis, S., Fessler, S., et al. (2021). Correction: The deubiquitylase USP9X controls ribosomal stalling. J Cell Biol 220.

Davis, R. J., Welcker, M., and Clurman, B. E. (2014). Tumor suppression by the Fbw7 ubiquitin ligase: mechanisms and opportunities. Cancer Cell 26, 455-464.

de Bie, P., and Ciechanover, A. (2011). Ubiquitination of E3 ligases: self-regulation of the ubiquitin system via proteolytic and non-proteolytic mechanisms. Cell Death Differ 18, 1393-1402.

Diefenbacher, M. E., Chakraborty, A., Blake, S. M., Mitter, R., Popov, N., Eilers, M., and Behrens, A. (2015). Usp28 counteracts Fbw7 in intestinal homeostasis and cancer. Cancer Res 75, 1181-1186.

Diefenbacher, M. E., Popov, N., Blake, S. M., Schulein-Volk, C., Nye, E., Spencer-Dene, B., Jaenicke, L. A., Eilers, M., and Behrens, A. (2014). The deubiquitinase USP28 controls intestinal homeostasis and promotes colorectal cancer. The Journal of clinical investigation 124, 3407-3418.

Fennell, D. A., Summers, Y., Cadranel, J., Benepal, T., Christoph, D. C., Lal, R., Das, M., Maxwell, F., Visseren-Grul, C., and Ferry, D. (2016). Cisplatin in the modern era: The backbone of first-line chemotherapy for non-small cell lung cancer. Cancer Treat Rev 44, 42-50.

Gandara, D. R., Hammerman, P. S., Sos, M. L., Lara, P. N., Jr., and Hirsch, F. R. (2015). Squamous cell lung cancer: from tumor genomics to cancer therapeutics. Clin Cancer Res 21, 2236-2243.

Guerin, D., Bair, K., Caravella, J.A., loannidis, S., Lancia, D.R., Li, H., Mischke, S., Ng, P.Y., Richard, D., Schiller, S., et al. (2017). THIENOPYRIDINE CARBOXAMIDES AS UBIQUITINSPECIFIC PROTEASE INHIBITORS In USA: World Intellectual Property Organization International Bureau, (USA).

Guerin, D., Ng, P. Y., Wang, Z., Shelekhin, T., Caravella, J., Zablocki, M.-M., Downing, J. R., Li, H., and loannidis, S. (2020). CARBOXAMIDES AS UBIQUITIN-SPECIFIC PROTEASE INHIBITORS In: World Intellectual Property Organization International Bureau. In World Intellectual Property Organization International Bureau. 
Hirsch, F. R., Govindan, R., Zvirbule, Z., Braiteh, F., Rittmeyer, A., Belda-Iniesta, C., Isla, D., Cosgriff, T., Boyer, M., Ueda, M., et al. (2017). Efficacy and Safety Results From a Phase II, Placebo-Controlled Study of Onartuzumab Plus First-Line Platinum-Doublet Chemotherapy for Advanced Squamous Cell Non-Small-Cell Lung Cancer. Clin Lung Cancer 18, 43-49.

Isaka, T., Nakayama, H., Yokose, T., Ito, H., Katayama, K., Yamada, K., and Masuda, M. (2017). Platinum-Based Adjuvant Chemotherapy for Stage II and Stage III Squamous Cell Carcinoma of the Lung. Ann Thorac Cardiovasc Surg 23, 19-25.

Jackson, E. L., Willis, N., Mercer, K., Bronson, R. T., Crowley, D., Montoya, R., Jacks, T., and Tuveson, D. A. (2001). Analysis of lung tumor initiation and progression using conditional expression of oncogenic K-ras. Genes \& development 15, 3243-3248.

Jandke, A., Da Costa, C., Sancho, R., Nye, E., Spencer-Dene, B., and Behrens, A. (2011). The Fbox protein Fbw7 is required for cerebellar development. Dev Biol 358, 201-212.

Jones, H. B. L., Heilig, R., Fischer, R., Kessler, B. M., and Pinto-Fernandez, A. (2021). ABPP-HT - High-Throughput Activity-Based Profiling of Deubiquitylating Enzyme Inhibitors in a Cellular Context. Front Chem 9, 640105.

Kan, Z., Jaiswal, B. S., Stinson, J., Janakiraman, V., Bhatt, D., Stern, H. M., Yue, P., Haverty, P. M., Bourgon, R., Zheng, J., et al. (2010). Diverse somatic mutation patterns and pathway alterations in human cancers. Nature 466, 869-873.

Knobel, P. A., Belotserkovskaya, R., Galanty, Y., Schmidt, C. K., Jackson, S. P., and Stracker, T. H. (2014). USP28 Is Recruited to Sites of DNA Damage by the Tandem BRCT Domains of 53BP1 but Plays a Minor Role in Double-Strand Break Metabolism. Molecular and cellular biology 34, 2062-2074.

Liao, R. G., Watanabe, H., Meyerson, M., and Hammerman, P. S. (2012). Targeted therapy for squamous cell lung cancer. Lung Cancer Manag 1, 293-300.

Muzumdar, M. D., Tasic, B., Miyamichi, K., Li, L., and Luo, L. (2007). A global doublefluorescent Cre reporter mouse. Genesis 45, 593-605.

Novello, S., Scagliotti, G. V., Sydorenko, O., Vynnychenko, I., Volovat, C., Schneider, C. P., Blackhall, F., McCoy, S., Hei, Y. J., and Spigel, D. R. (2014). Motesanib plus carboplatin/paclitaxel in patients with advanced squamous non-small-cell lung cancer: results from the randomized controlled MONET1 study. J Thorac Oncol 9, 1154-1161.

Panyain, N., Godinat, A., Lanyon-Hogg, T., Lachiondo-Ortega, S., Will, E. J., Soudy, C., Mondal, M., Mason, K., Elkhalifa, S., Smith, L. M., et al. (2020). Discovery of a Potent and Selective Covalent Inhibitor and Activity-Based Probe for the Deubiquitylating Enzyme UCHL1, with Antifibrotic Activity. J Am Chem Soc 142, 12020-12026.

Pinto-Fernandez, A., Davis, S., Schofield, A. B., Scott, H. C., Zhang, P., Salah, E., Mathea, S., Charles, P. D., Damianou, A., Bond, G., et al. (2019). Comprehensive Landscape of Active Deubiquitinating Enzymes Profiled by Advanced Chemoproteomics. Front Chem 7, 592.

Popov, N., Wanzel, M., Madiredjo, M., Zhang, D., Beijersbergen, R., Bernards, R., Moll, R., Elledge, S. J., and Eilers, M. (2007). The ubiquitin-specific protease USP28 is required for MYC stability. Nat Cell Biol 9, 765-774.

Prieto-Garcia, C., Hartmann, O., Reissland, M., Braun, F., Fischer, T., Walz, S., Schulein-Volk, C., Eilers, U., Ade, C. P., Calzado, M. A., et al. (2020). Maintaining protein stability of Np63 via USP28 is required by squamous cancer cells. EMBO Mol Med 12, e11101.

Ruiz, E. J., Diefenbacher, M. E., Nelson, J. K., Sancho, R., Pucci, F., Chakraborty, A., Moreno, P., Annibaldi, A., Liccardi, G., Encheva, V., et al. (2019). LUBAC determines chemotherapy resistance in squamous cell lung cancer. J Exp Med 216, 450-465. 
Scagliotti, G. V., Parikh, P., von Pawel, J., Biesma, B., Vansteenkiste, J., Manegold, C., Serwatowski, P., Gatzemeier, U., Digumarti, R., Zukin, M., et al. (2008). Phase III study comparing cisplatin plus gemcitabine with cisplatin plus pemetrexed in chemotherapynaive patients with advanced-stage non-small-cell lung cancer. J Clin Oncol 26, 3543-3551.

Schauer, N. J., Magin, R. S., Liu, X., Doherty, L. M., and Buhrlage, S. J. (2019). Advances in Discovering Deubiquitinating Enzyme (DUB) Inhibitors. J Med Chem.

Schonhuber, N., Seidler, B., Schuck, K., Veltkamp, C., Schachtler, C., Zukowska, M., Eser, S., Feyerabend, T. B., Paul, M. C., Eser, P., et al. (2014). A next-generation dual-recombinase system for time- and host-specific targeting of pancreatic cancer. Nature medicine 20, 1340-1347.

Turnbull, A. P., loannidis, S., Krajewski, W. W., Pinto-Fernandez, A., Heride, C., Martin, A. C. L., Tonkin, L. M., Townsend, E. C., Buker, S. M., Lancia, D. R., et al. (2017). Molecular basis of USP7 inhibition by selective small-molecule inhibitors. Nature 550, 481-486.

Wrigley, J. D., Gavory, G., Simpson, I., Preston, M., Plant, H., Bradley, J., Goeppert, A. U., Rozycka, E., Davies, G., Walsh, J., et al. (2017). Identification and Characterization of Dual Inhibitors of the USP25/28 Deubiquitinating Enzyme Subfamily. ACS Chem Biol 12, 31133125.

Zablocki, M.-M., Guerin, D., Ng, P. Y., Wang, Z., Shelekhin, T., Caravella, J., Li, H., and loannidis, S. (2019). CARBOXAMIDES AS UBIQUITIN-SPECIFIC PROTEASE INHIBITORS In: World Intellectual Property Organization International Bureau, (France). In USA: World Intellectual Property Organization International Bureau, (USA). 
1 Table 1: Primers for qPCR

\begin{tabular}{|l|l|l|}
\hline Name & Primer $\left(\mathbf{5}^{\prime} \mathbf{- 3} \mathbf{3}^{\prime}\right)$ & \\
\hline & Forward & Reverse \\
\hline ACTIN & GAAAATCTGGCACCACACCT & TAGCACAGCCTGGATAGCAA \\
\hline USP28 & ACTCAGACTATTGAACAGATGTACTGC & CTGCATGCAAGCGATAAGG \\
\hline MYC & TCTCCTTGCAGCTGCTTAG & GTCGTAGTCGAGGTCATAG \\
\hline
\end{tabular}

2

3 Table 2: List of Reagents

\begin{tabular}{|c|c|c|}
\hline REAGENT & SOURCE & IDENTIFIER \\
\hline \multicolumn{3}{|l|}{ Antibodies } \\
\hline Rabbit anti-CK5 & Abcam & ab52635 \\
\hline Rabbit anti-c-Myc & Abcam & ab32072 \\
\hline Goat anti-GFP & Abcam & ab6673 \\
\hline Rabbit anti-Ki67 & Abcam & ab16667 \\
\hline Rabbit anti-TTF1 & Abcam & $a b 76013$ \\
\hline Rabbit anti-USP28 & Abcam & ab126604 \\
\hline Rabbit anti-USP25 & Abcam & ab187156 \\
\hline Rabbit anti-USP11 & Abcam & ab109232 \\
\hline Rabbit anti-USP36 & Abcam & $a b 102565$ \\
\hline Rabbit anti-actin & Abcam & ab8227 \\
\hline Rabbit anti-USP28 & Atlas & HPA006779 \\
\hline Rabbit anti- $\Delta \mathrm{p} 63$ & Biolegend & 619001 \\
\hline Mouse anti-C-Jun & BD Biosciences & 610326 \\
\hline Rabbit anti-FBW7 & Bethyl & A301-721A \\
\hline Rabbit anti-USP7 & Enzo & BML-PW0540 \\
\hline Mouse anti-GAPDH & Invitrogen & MA5-15738 \\
\hline Rabbit anti-Sftpc & Millipore & ab3786 \\
\hline Rabbit anti-caspase 3 active & R\&D Systems & AF835 \\
\hline Rat anti-HA & Roche & 11666606001 \\
\hline Mouse anti-tubulin & Sigma & T5168 \\
\hline \multicolumn{3}{|l|}{ Virus Strains } \\
\hline Adeno-CMV-Cre & UI viral vector core & VVC-U of lowa-5-HT \\
\hline Adeno-CMV-FIp & Ul viral vector core & VVC-U of lowa-530HT \\
\hline \multicolumn{3}{|c|}{ Chemicals, Peptides, and Recombinant Proteins } \\
\hline Doxycycline hyclate & Sigma & D9891 \\
\hline Tamoxifen & Sigma & T5648 \\
\hline
\end{tabular}


A

bioRxiv preprint doi: https://doi. org/10.1101/2020.11.17.377705; this version posted July 15,2021 . The copyright holder for this preprint (which was not certified by peer review) is the author/funder, who has granted_bioRxiv a license to display the preprint in perpetuity. It is
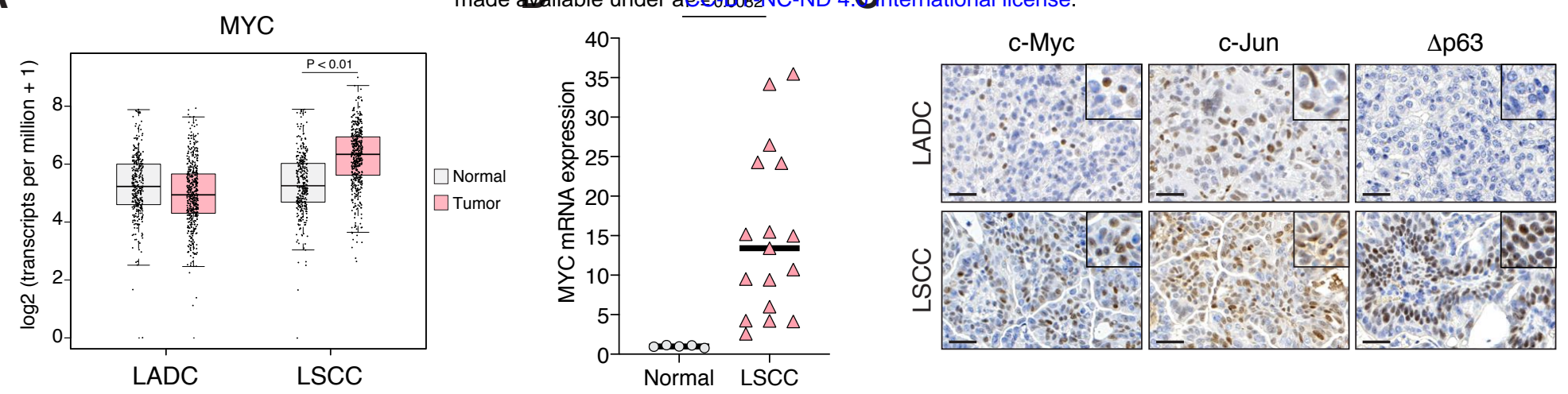

D
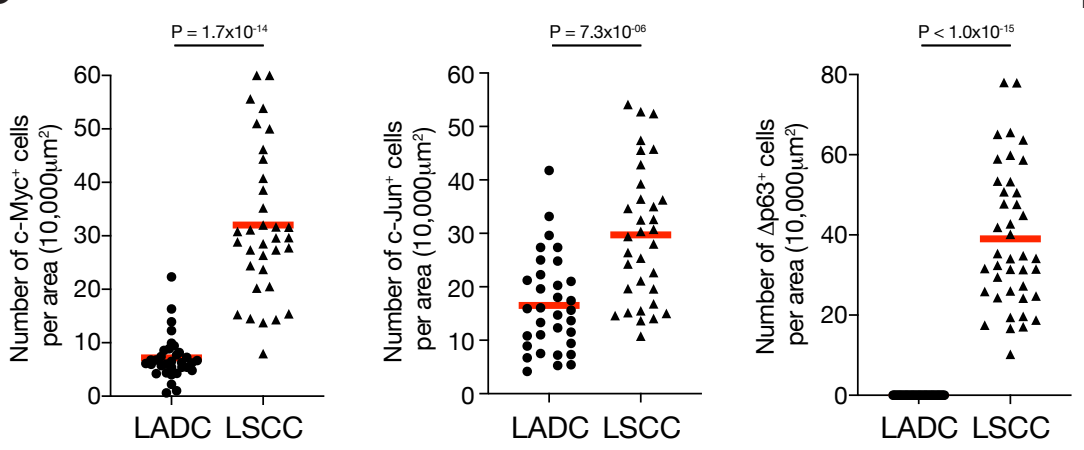

$\mathbf{F}$

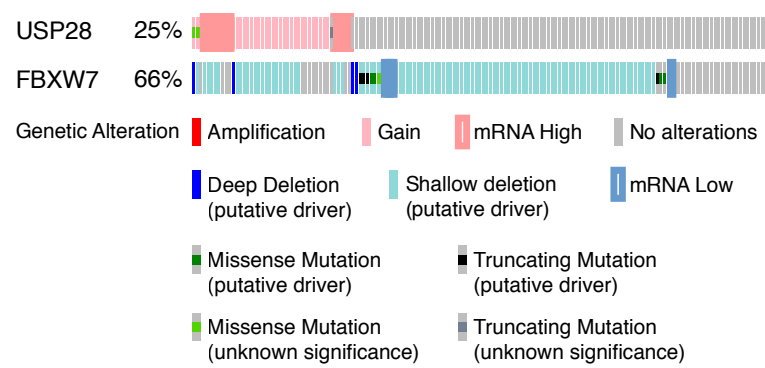

$\mathbf{E}$

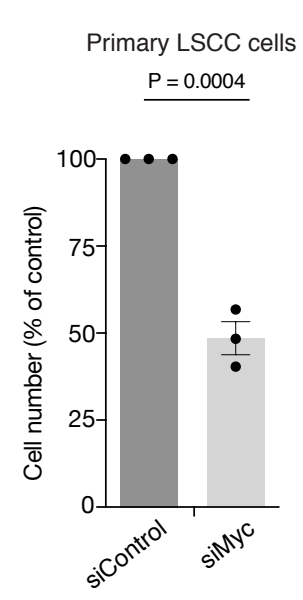

G

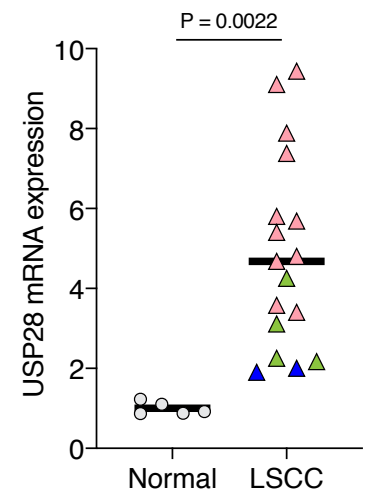

H

Primary LSCC cells

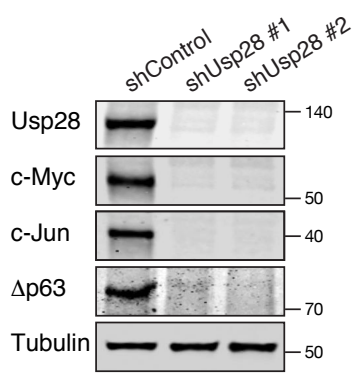

LSCC 
bioRxiv preprint doi: https://doi.org/10.1101/2020.11.17.377705; this version posted July 15,2021 . The copyright holder for this preprint (which was not certified by peer review) is the author/funder, who has granted bioRxiv a license to display the preprint in perpetuity. It is

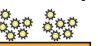
KFCU model +CMV-Flp

K-Ras /NStop-NII]-

Conditional KRas activation

(G12D point mutant)

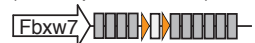

Conditional Fbxw7 deletion

R26 /Stop-NCre

Conditional $\mathrm{Cre}^{\mathrm{ERT}}$ expression

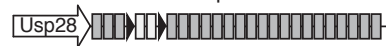

Conditional Usp28 deletion made available under aCC-BY-NC-ND 4.0 International license.

B

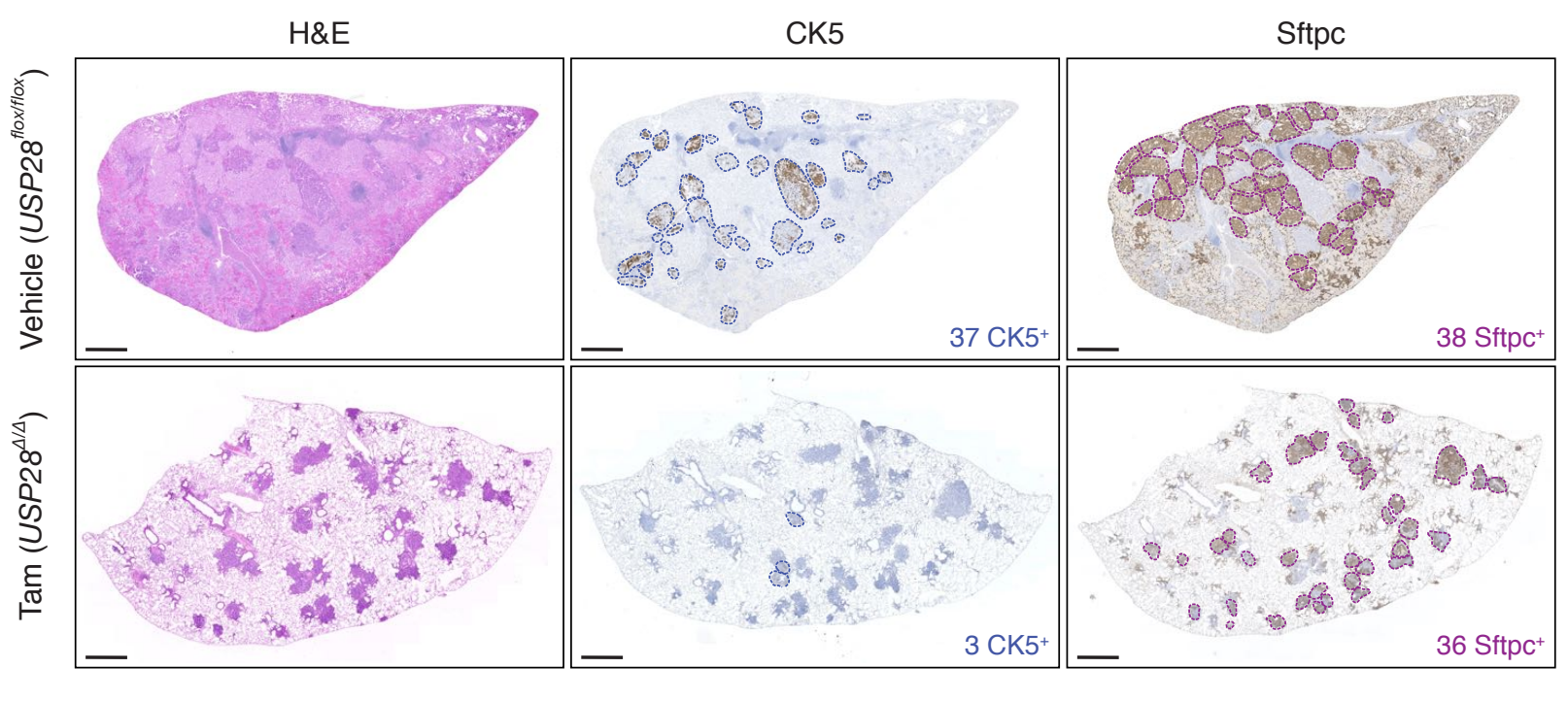

C

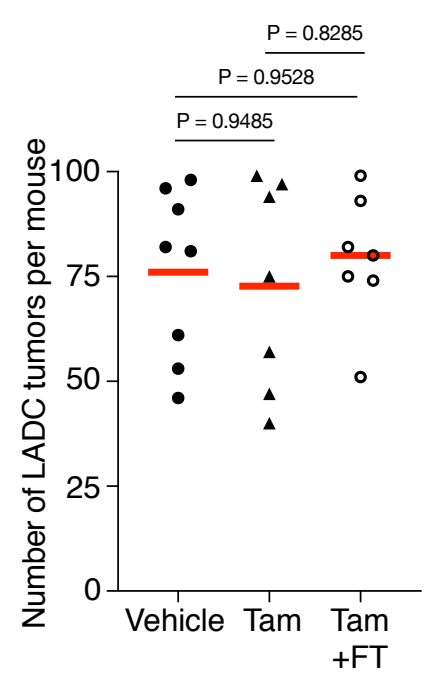

F

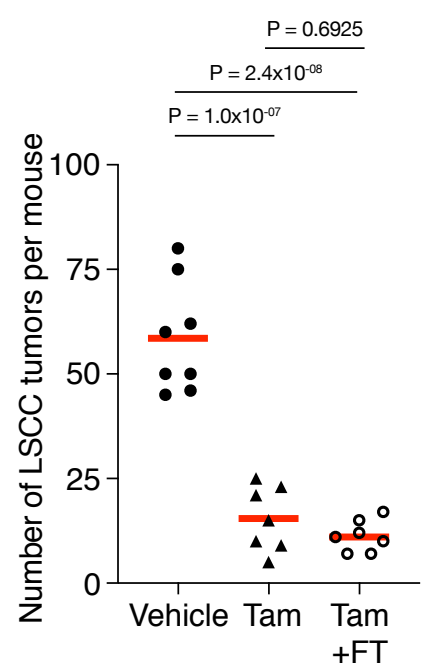

D

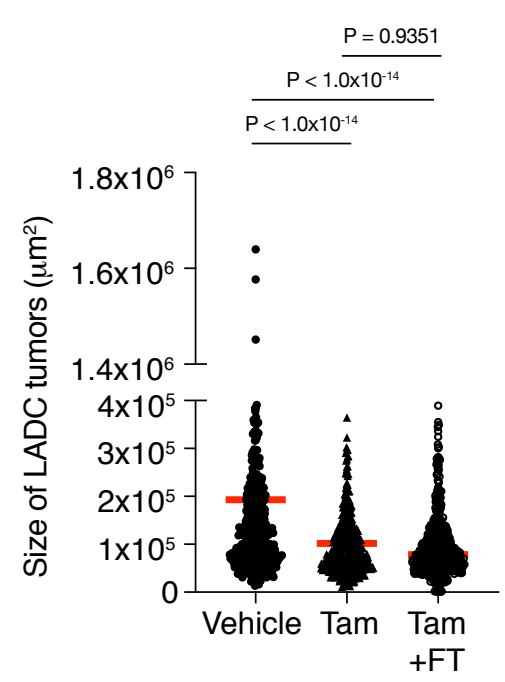

G

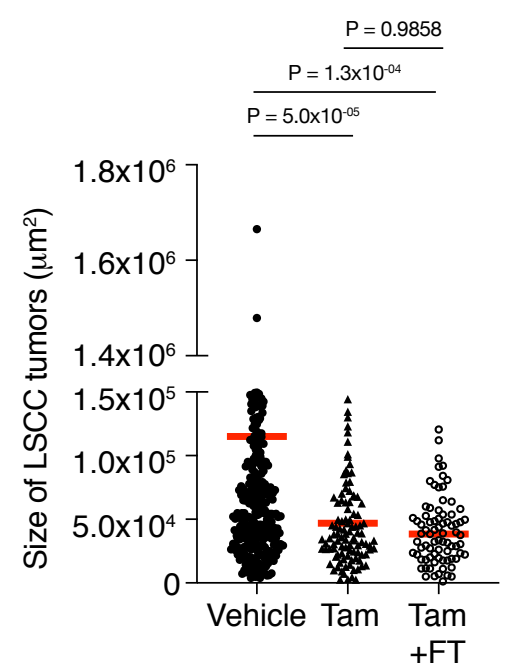

E

LADC

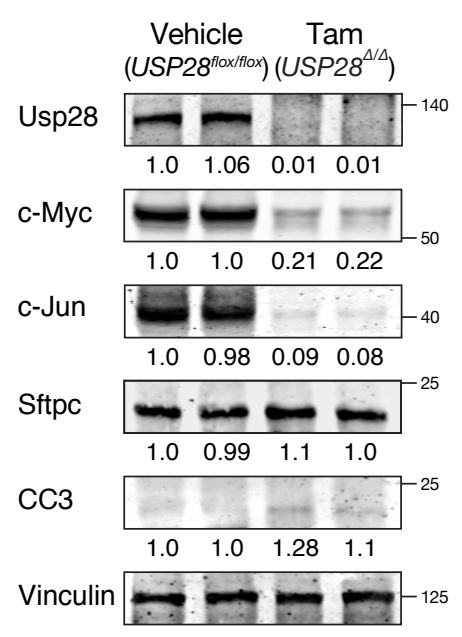

H

LSCC

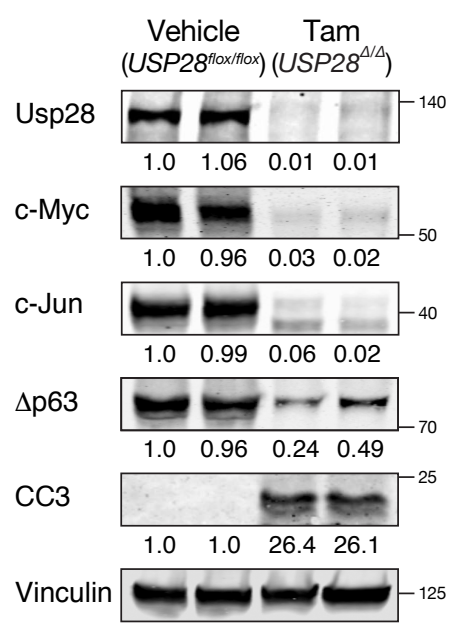

\section{Figure 2}


bioRxiv preprint doi: https://doi.org/10.1101/2020.11.17.377705; this version posted July 15, 2021. The copyright holder for this preprint (which was not certified by peer review) is the author/funder, who has granted bioRxiv a license to display the preprint in perpetuity. It is made available under aCC-BY-NC-ND 4.0 International license.

A

\section{KPCU model +CMV-FIp}

K-Ras NStop-N|W-

Conditional KRas activation

(G12D point mutant)

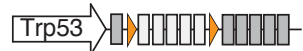

Conditional $\mathrm{p} 53$ deletion

R26 NStop-Cre

Conditional Cre ${ }^{\mathrm{ERT}}$ expression

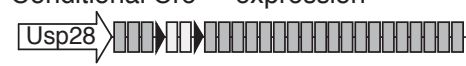

Conditional Usp28 deletion

$\mathrm{R} 26$ HT $\mathrm{m}$ -

Conditional activation of GFP expression

Cre-dependent

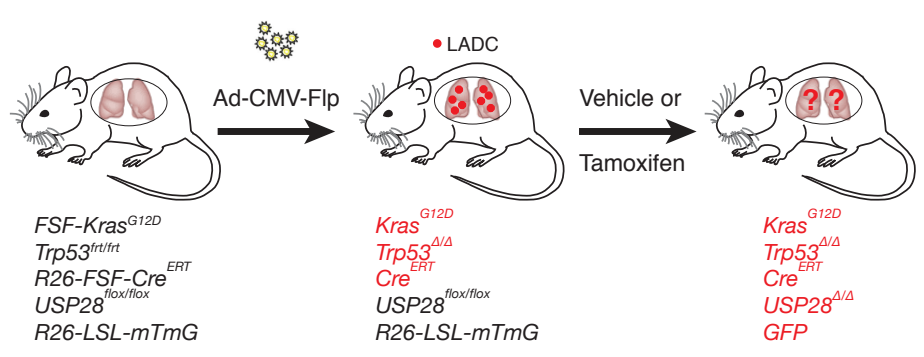

C

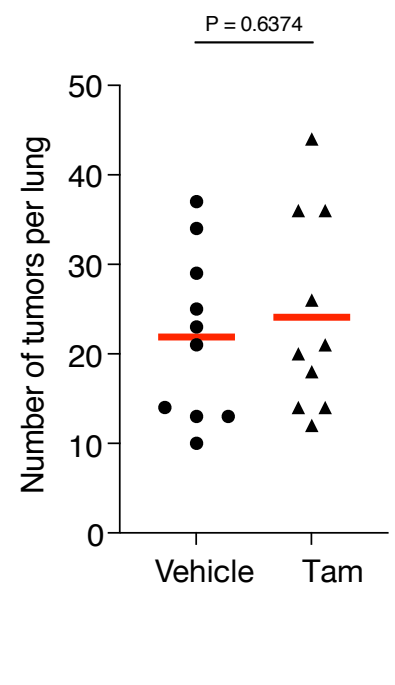

D

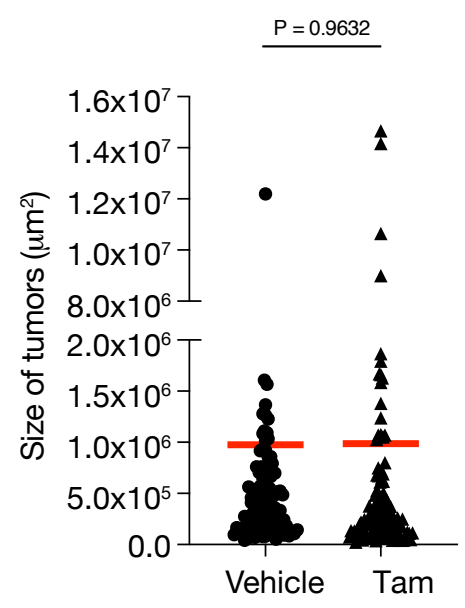

E

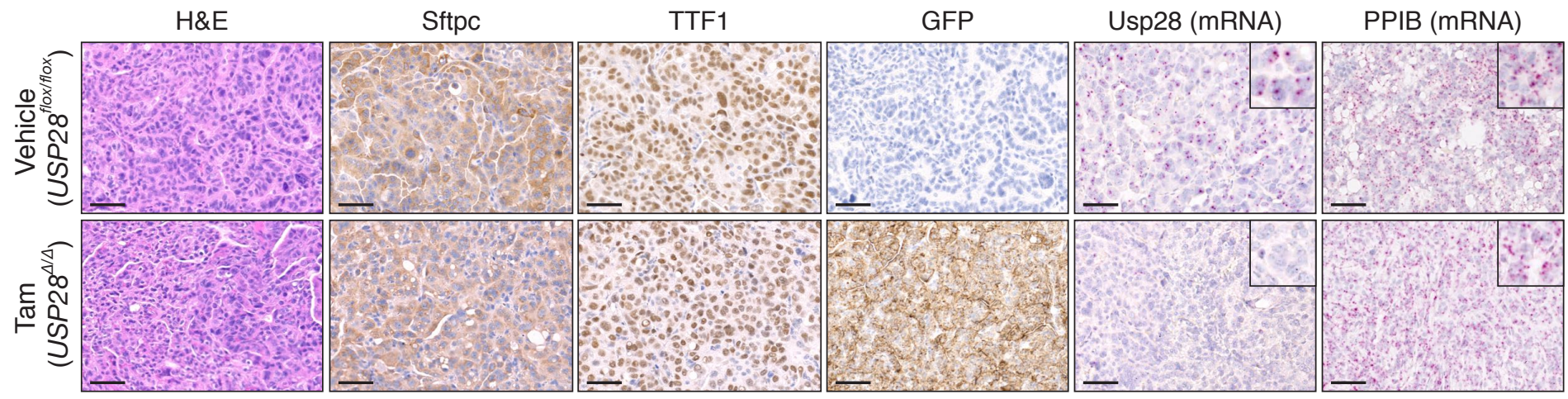



made available under aCC-BY-NC-ND 4.0 International license.<smiles>Cc1ccc2c(N)c(C(=O)NC3CCc4cc(N5CC6CC(C5)N6)ccc4C3)sc2n1</smiles>

FT206

$\mathrm{N}-((2 S)-6-(3,8-d i a z a b i c y c l o[3.2 .1]$ octan-3-yl)-I,2,3,4-tetrahydronaphthalen2-yl)-3-amino-6-methylthieno [2,3-b] pyridine-2-carboxamide

B

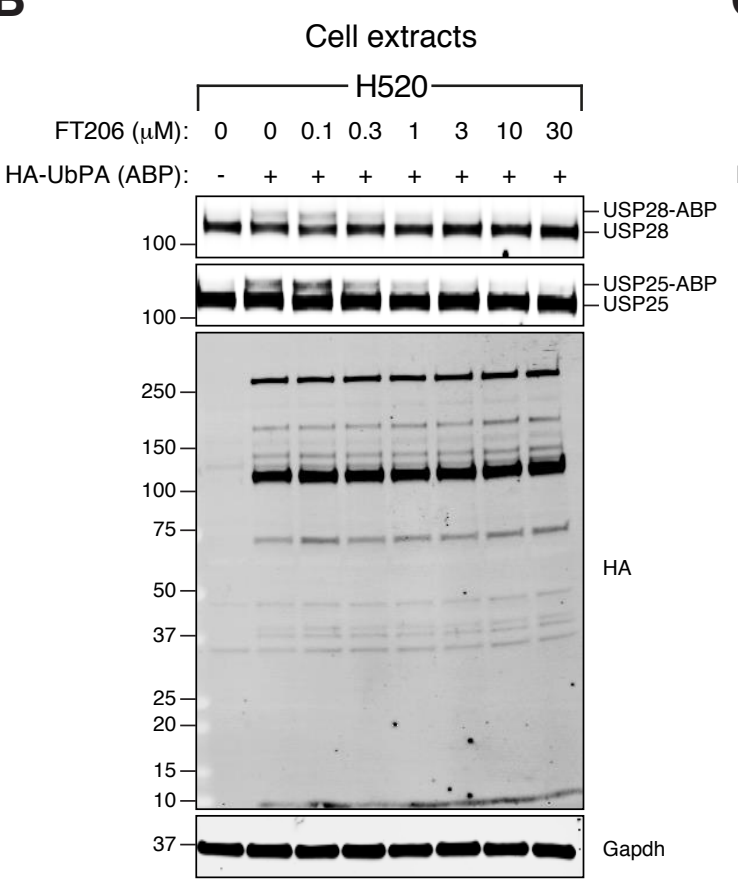

C

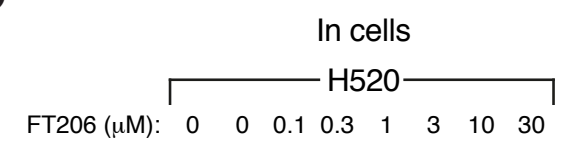

HA-UbPA (ABP)

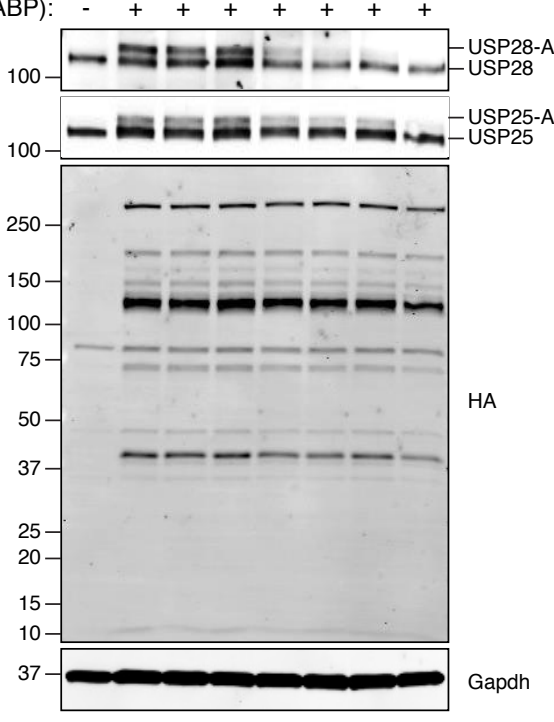

E

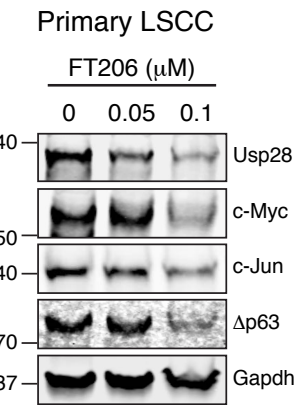

$\mathbf{F}$

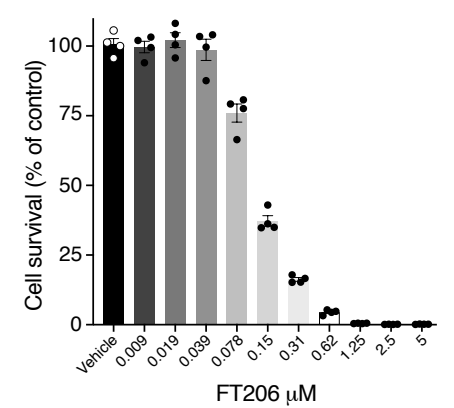

D

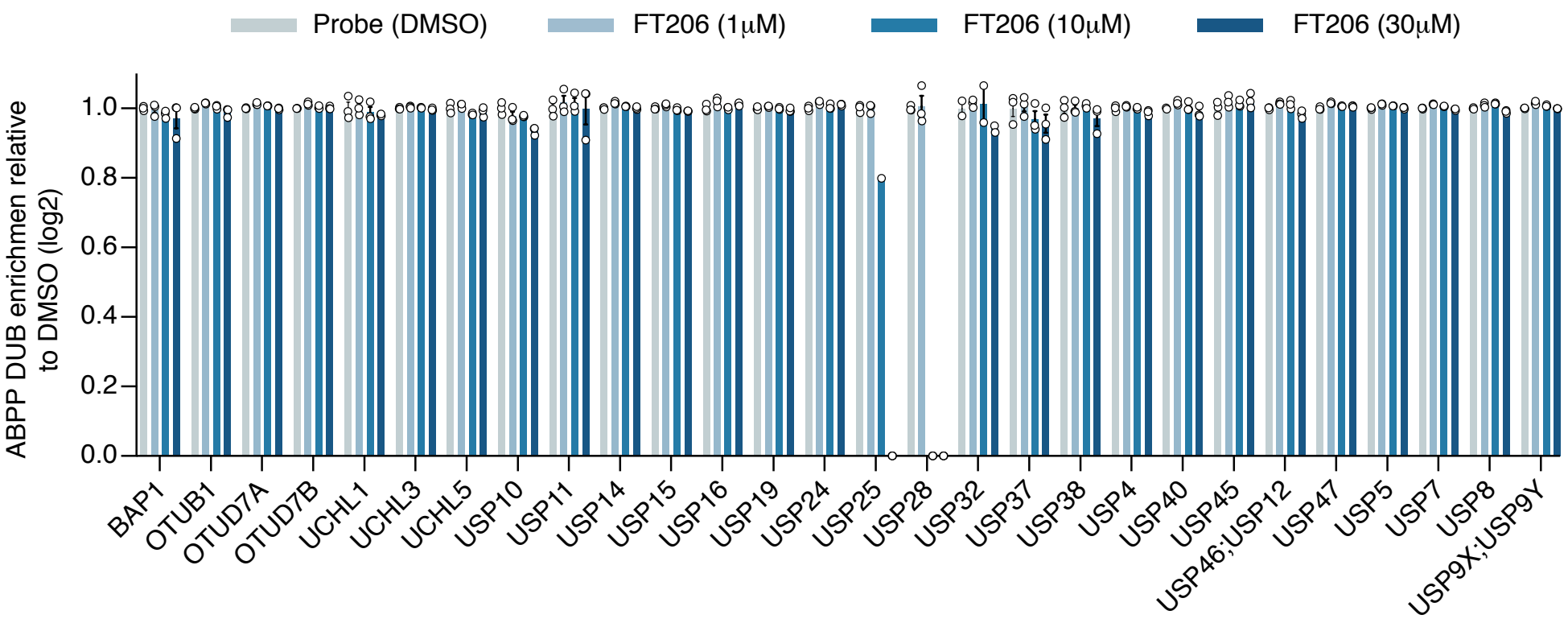


bioRxiv preprint doi: https://doi.org/10.1101/2020.11.17.377705; this version posted July 15, 2021. The copyright holder for this preprint

A (which was not certified by peer review) is the author/funder who has granted bioRxiv a license to display the preprint in perpetuity. It is \%

KF model +CMV-Cre

K-Ras Stop - N][-

Conditional KRas activation

(G12D point mutant)

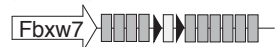

Conditional Fbxw7 deletion made available under aCC-BY-NC-ND 4.0 International license.

made available under aCC-BY-NC-ND 4.0 international license.

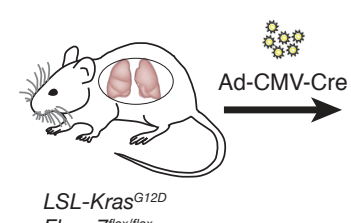

LSL-Kras
Fbxw $67^{\text {flox/flox }}$
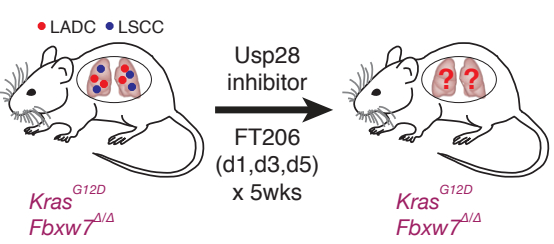

Kras $^{\mathrm{G}}{ }^{-1 / 4}$
Fbxw $^{\prime / 4}$

B

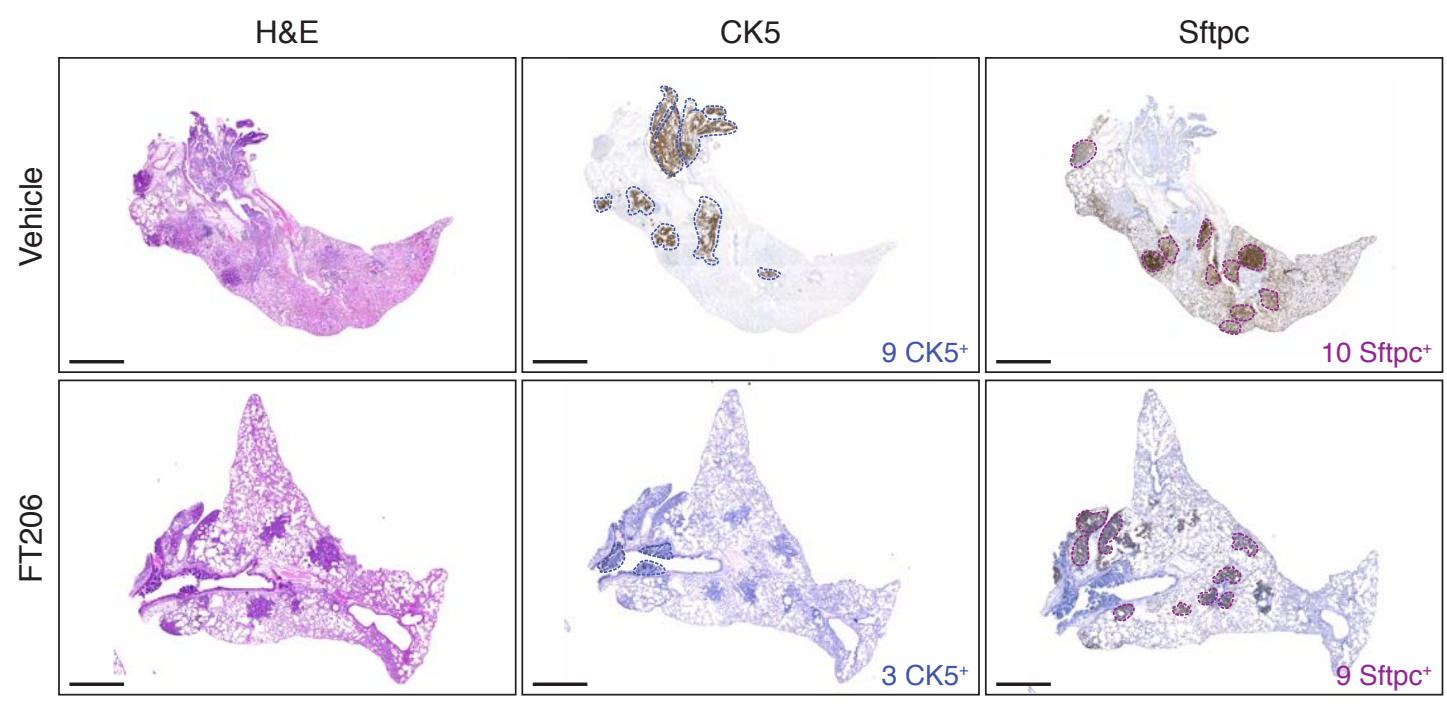

C

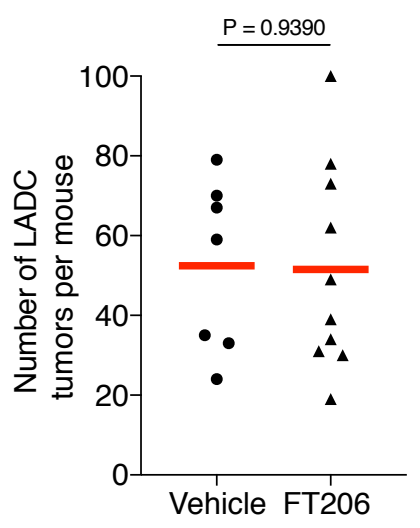

D

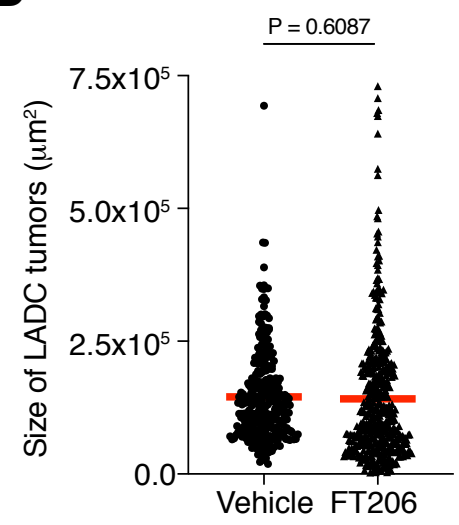

E

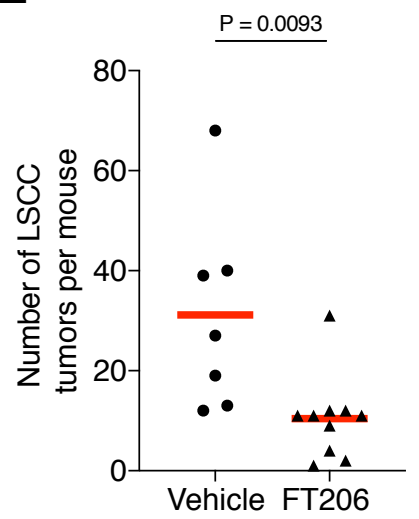

$\mathbf{F}$

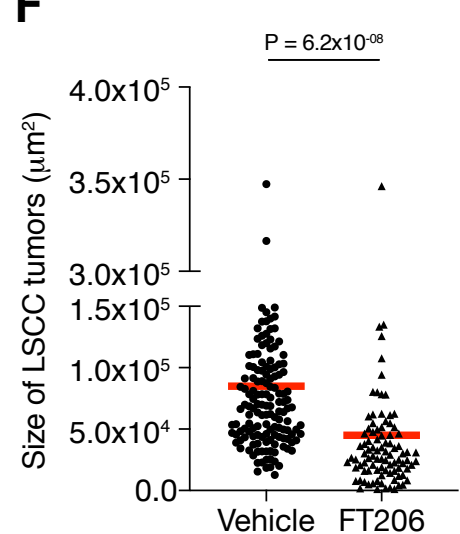

G

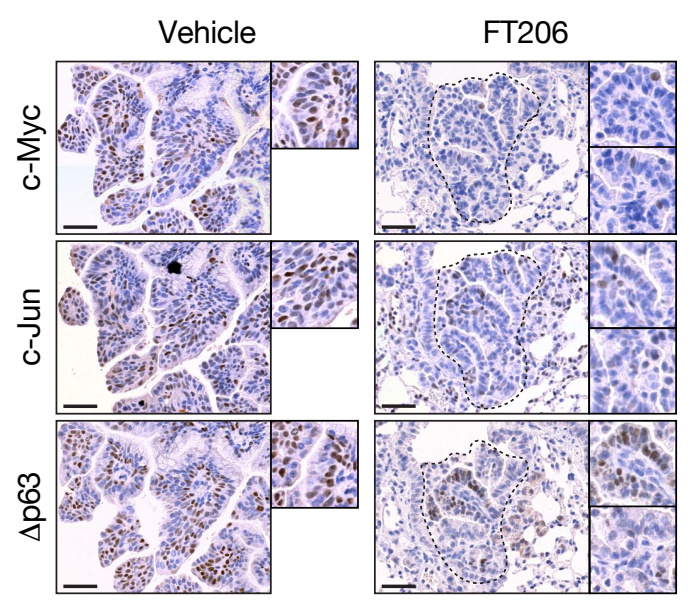

H
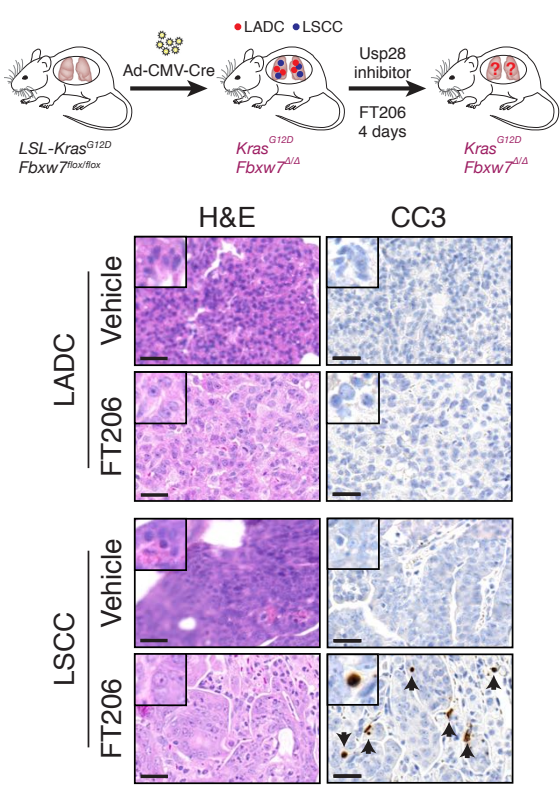

I

$P=2.3 \times 10^{-07}$

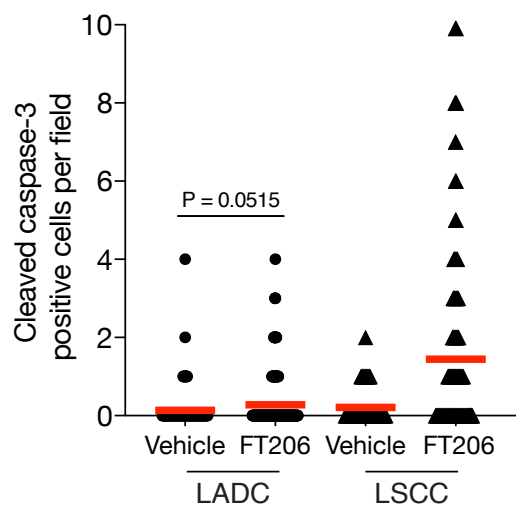

\section{Figure 5}


bioRxiv preprint doi: https://doi.org/10.1101/2020.11.17.377705; this version posted July 15, 2021. The copyright holder for this preprint

(which was not certified by peer review) is the author/funder, who has granted bioRxiv a license to display the preprint in perpetuity. It is

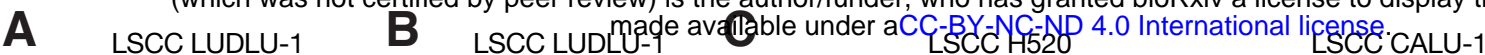

LSCC LUDLU-1

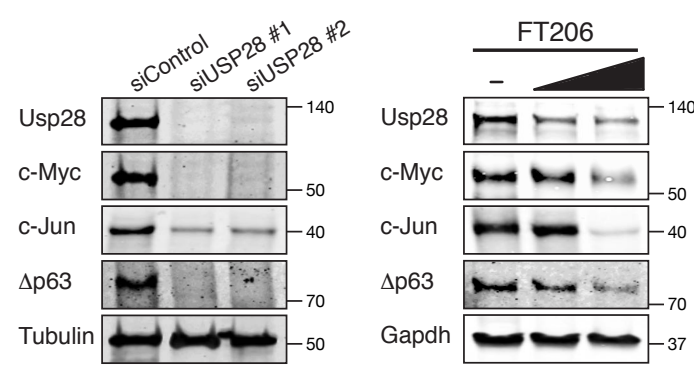

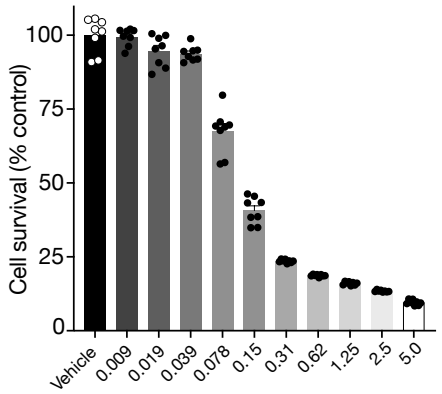

$\mathrm{FT} 206 \mu \mathrm{M}$

G

LSCC H520

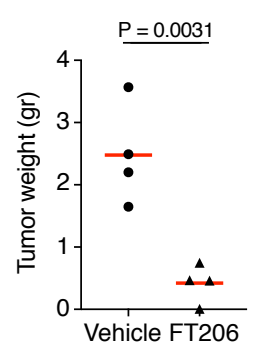

H
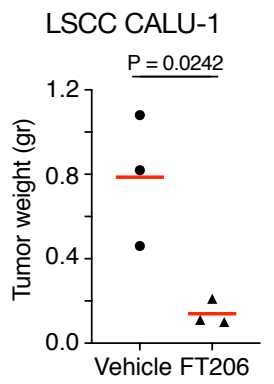

I

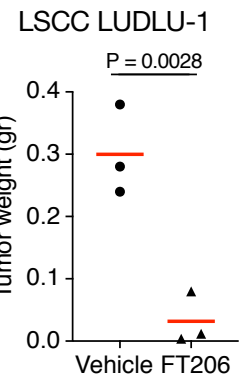

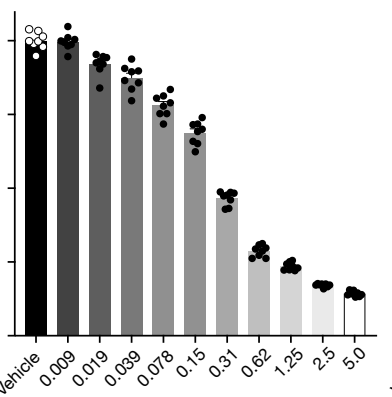

FT206 $\mu \mathrm{M}$

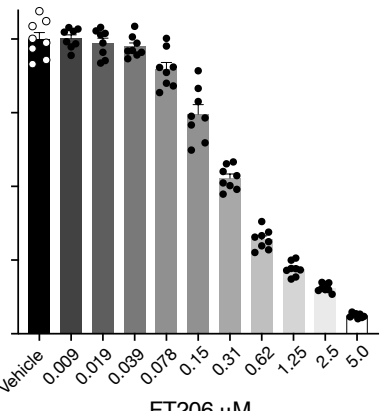

FT206 $\mu \mathrm{M}$

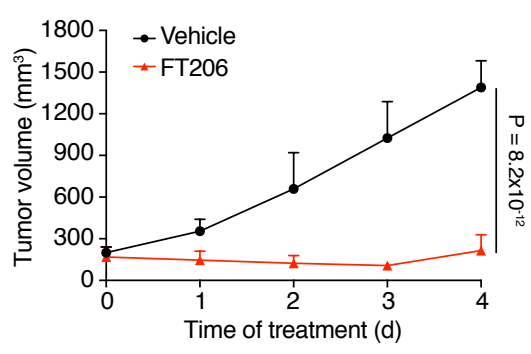

LSCC CALU-1

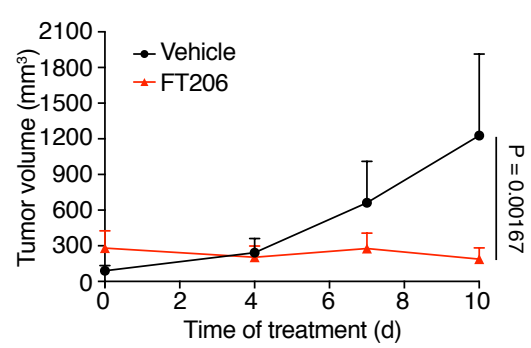

F

LSCC LUDLU-1

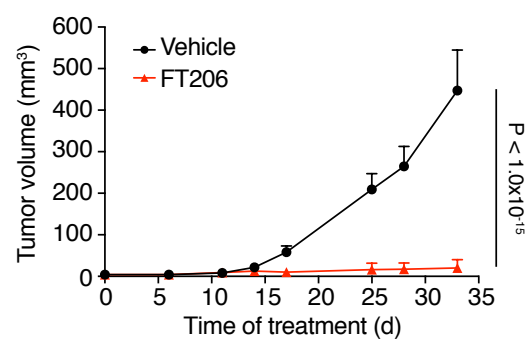

Figure 6 
(which was not certified by peer review) is the author/funder, who has granted bioRxiv a license to display the preprint in perpetuity. It is LSCC H226
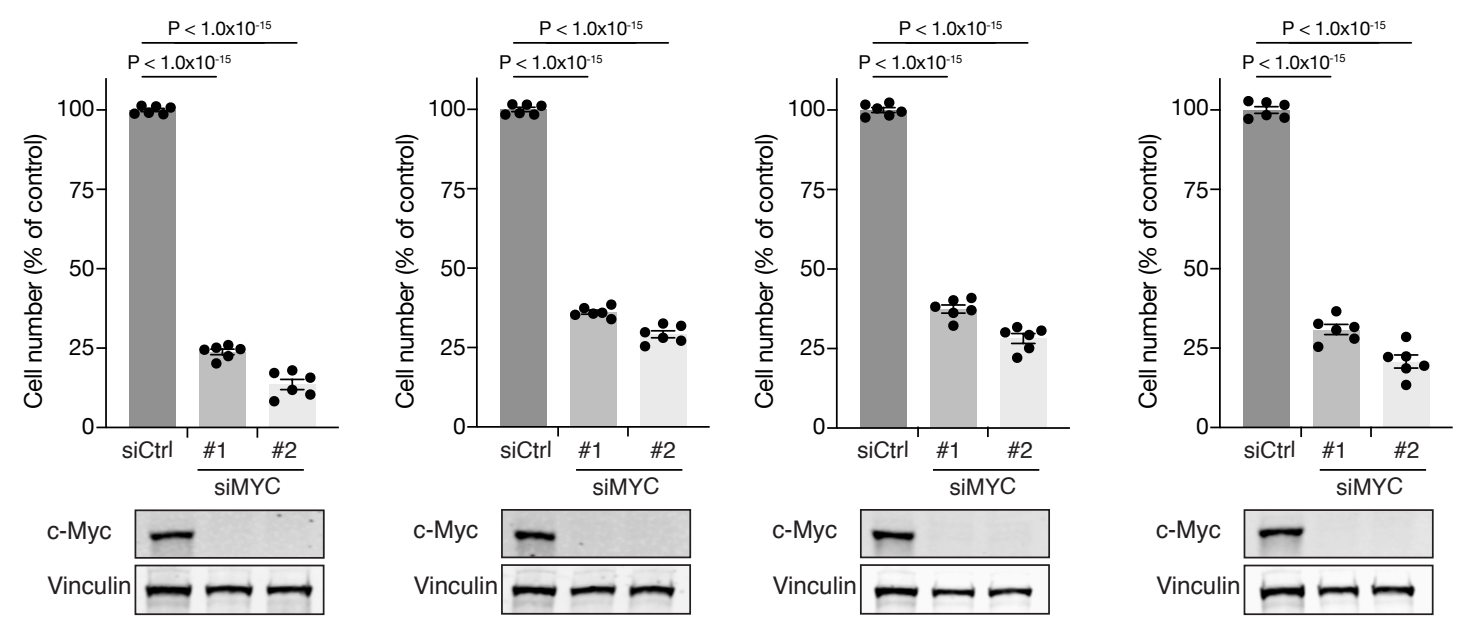

B
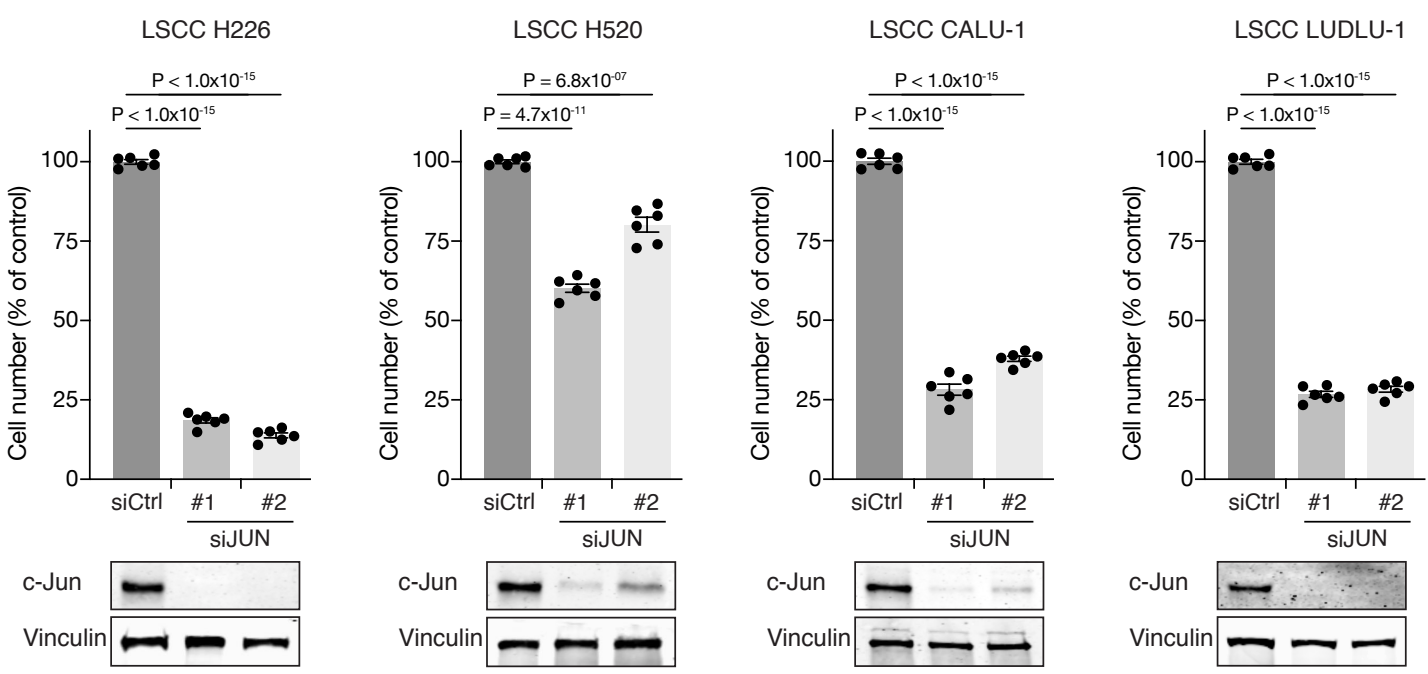

C
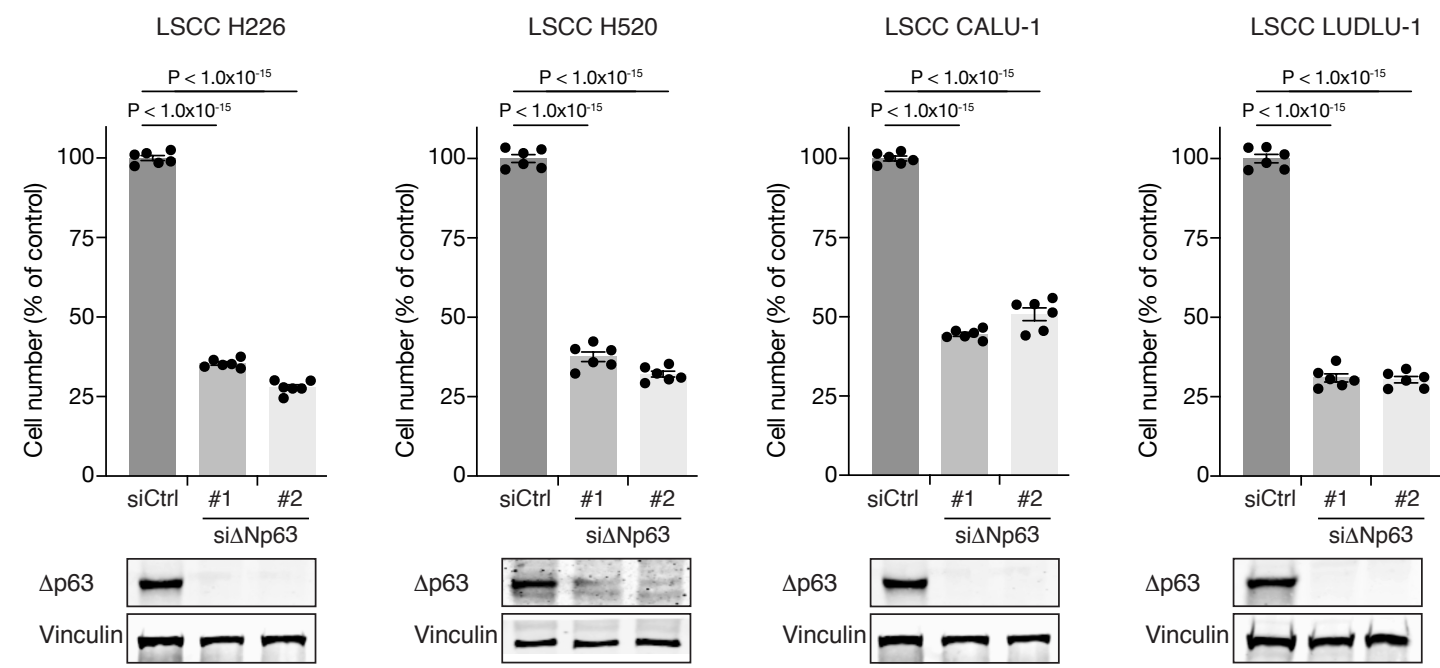

\section{Figure S1}


bioRxiv preprint doi: https://doi.org/10.1101/2020.11.17.377705; this version posted July 15,2021 . The copyright holder for this preprint (which was not certified by peer review) is the author/funder, who has granted bioRxiv a license to display the preprint in perpetuity. It is

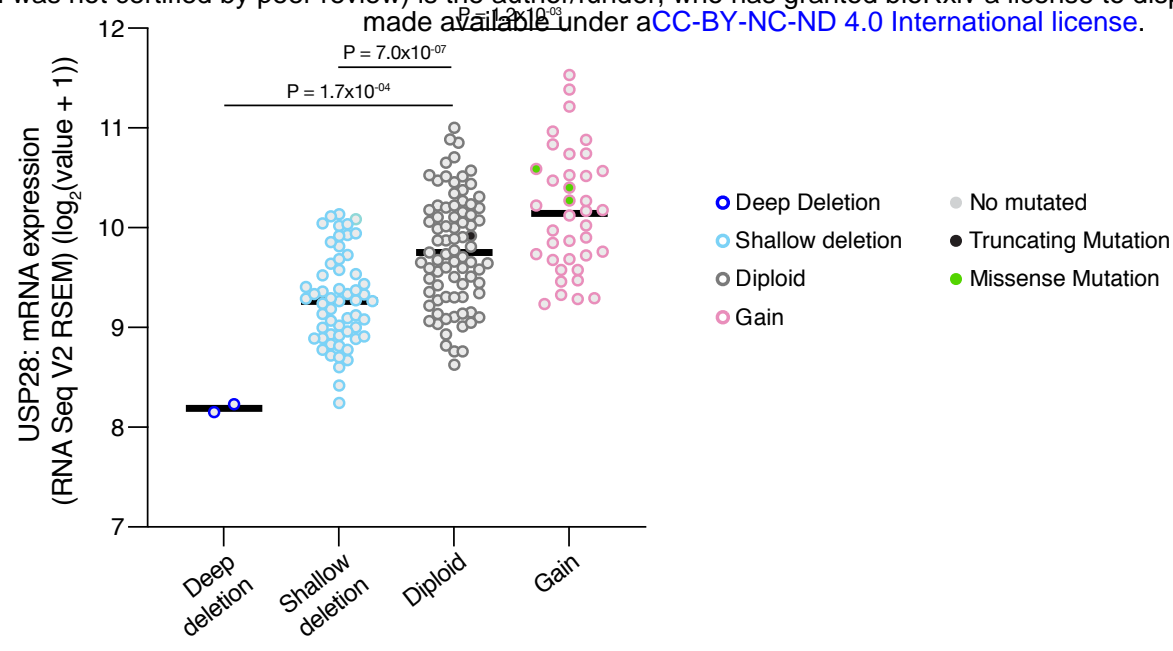

USP28: Putative copy-number alterations from GISTIC

B
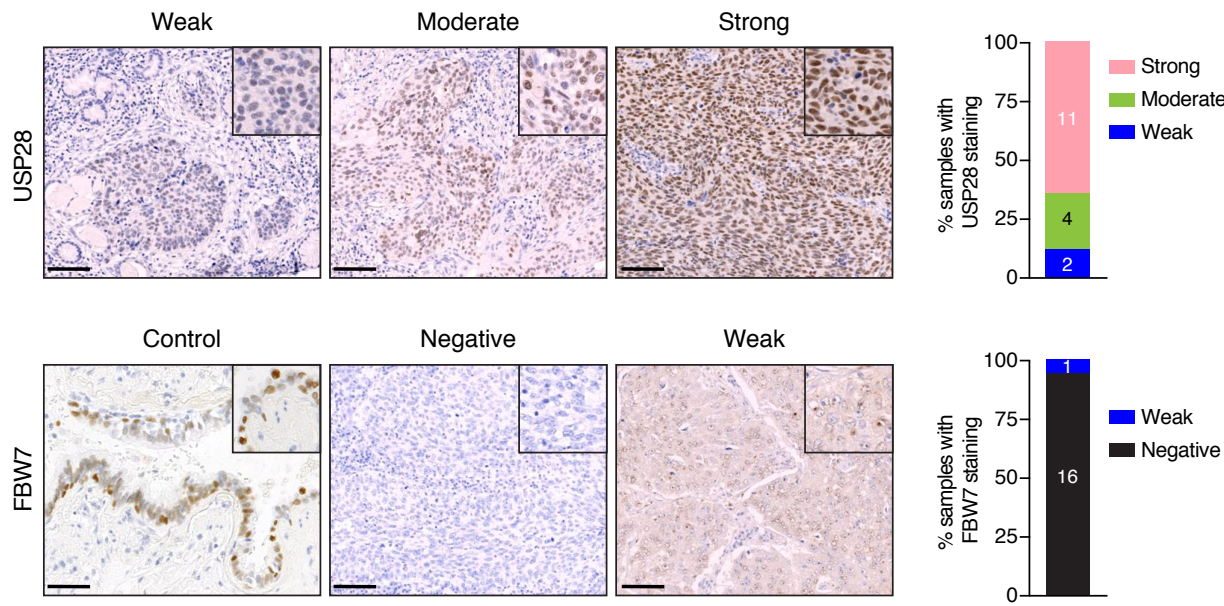

\section{Figure S2}


A bioRxiv preprint doi: https://doi.org/10.1101/2020.11.17.377705; this version posted July 15,2021 . The copyright holder for this preprint (which was not certified by peer review) is the author/funder, who bas granted bioRxiv a license to display the preprint in perpetuity. It is made available under aCC-BY-P

Targeting intron 4 Targeting Intron 4 and 5

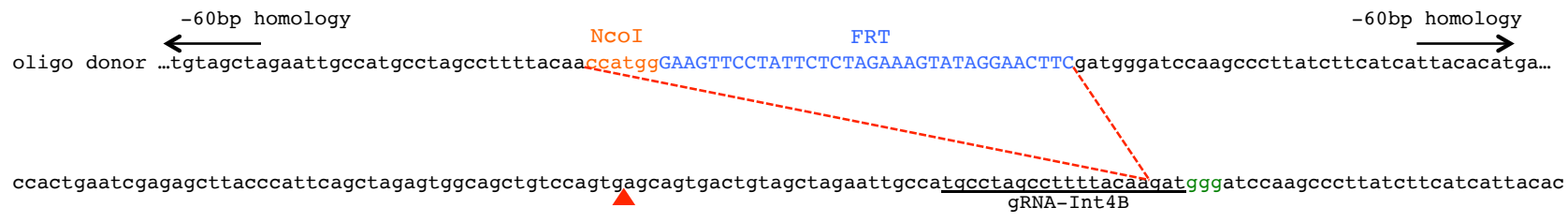
ggtgacttagctctcgaatgggtaagtcgatctcaccgtcgacaggtcactcgtcactgacatcgatcttaacggtacggatcggaaaatgttctaccctaggttcgggaatagaagtagtaatgtg gRNA-Int4A

Targeting intron 5

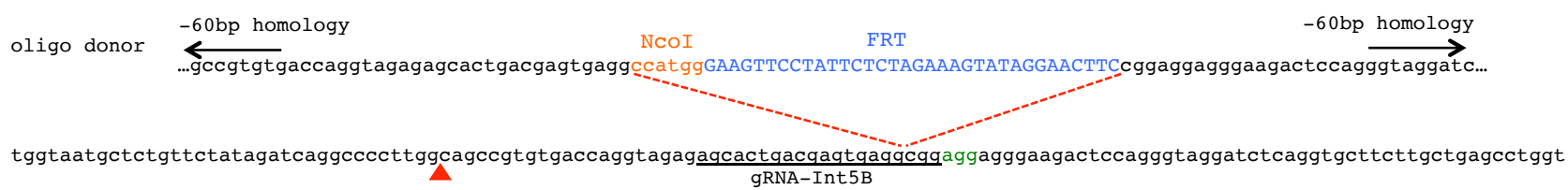
accattacgagacaagatatctagtccggggaaccgtcggcacactggtccatctctcgtgactgctcactccǵgctcctcccttctgaggtcccatcctagagtccacgaagaacgactcggacca

B
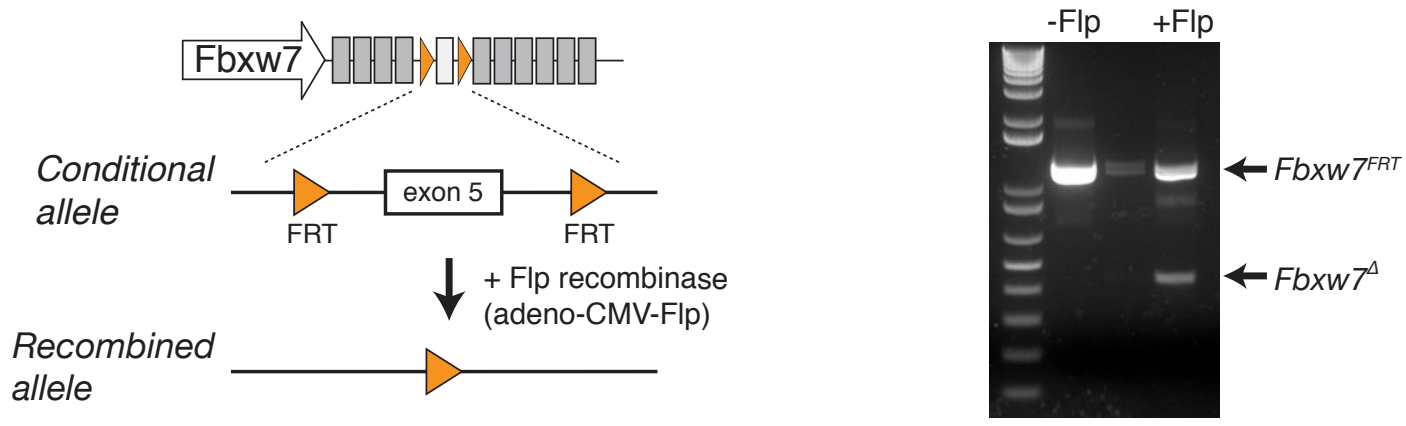

C
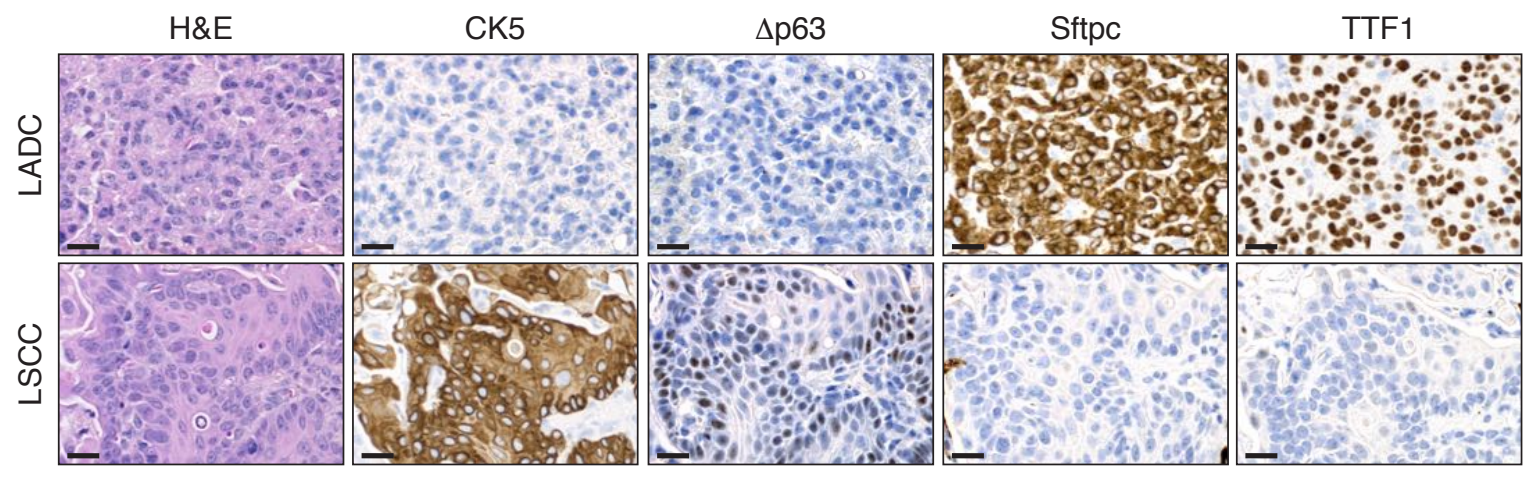

D

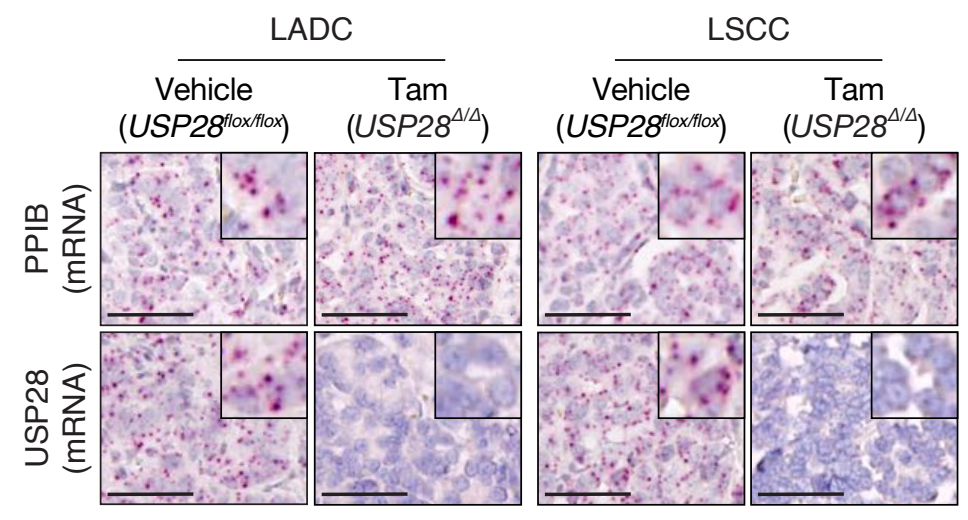

$\mathbf{E}$
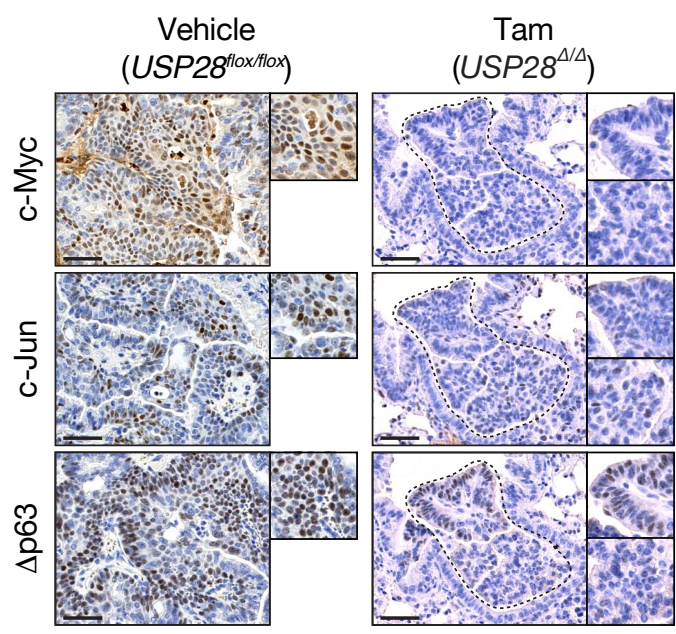

\section{Figure S3}


A bioRxiv preprint doi: https://doi.org/10.1101/2020.11.17.377705; this version posted July 15, 2021. The copyright holder for this preprint (which was not certified by peer review) is the author/funder, who has granted bioRxiv a license to display the preprint in perpetuity. It is made avaitaptoosnder aCC-BYY-NC-ND 40 IAtEnational license.

FT206 (uM): $0 \begin{array}{llllllllllllllll}0 & 0 & 0.1 & 0.3 & 1 & 3 & 10 & 30 & 0 & 0 & 0.1 & 0.3 & 1 & 3 & 10 & 30\end{array}$

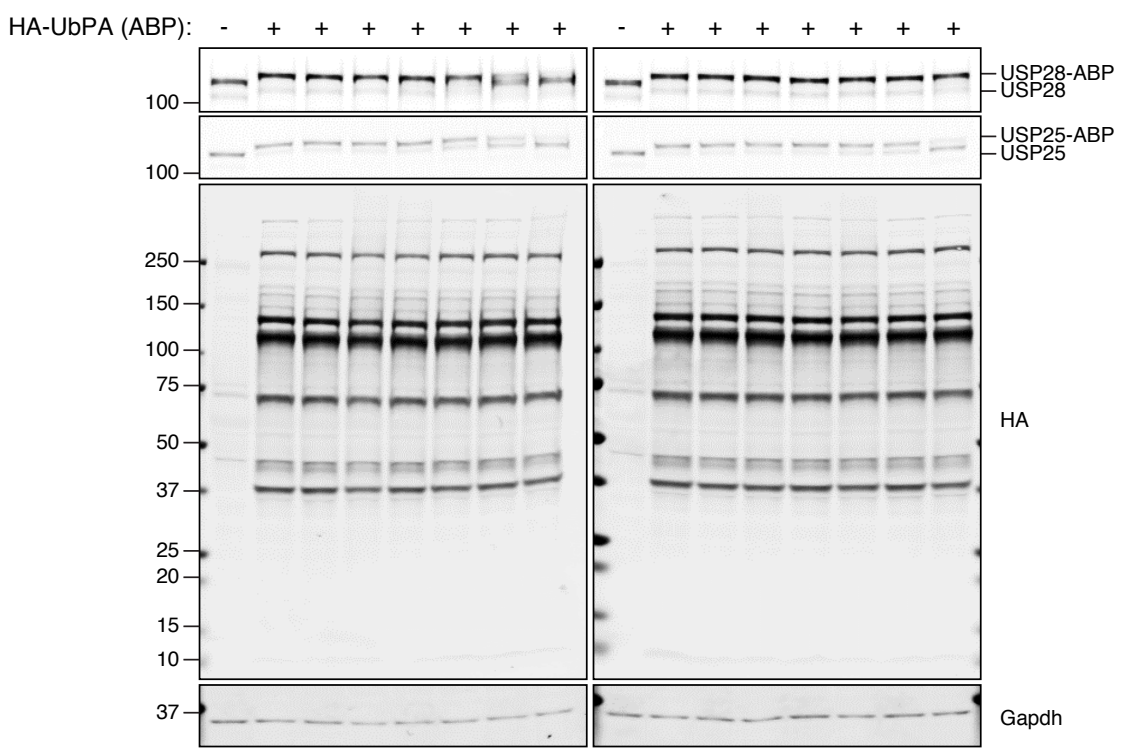

B
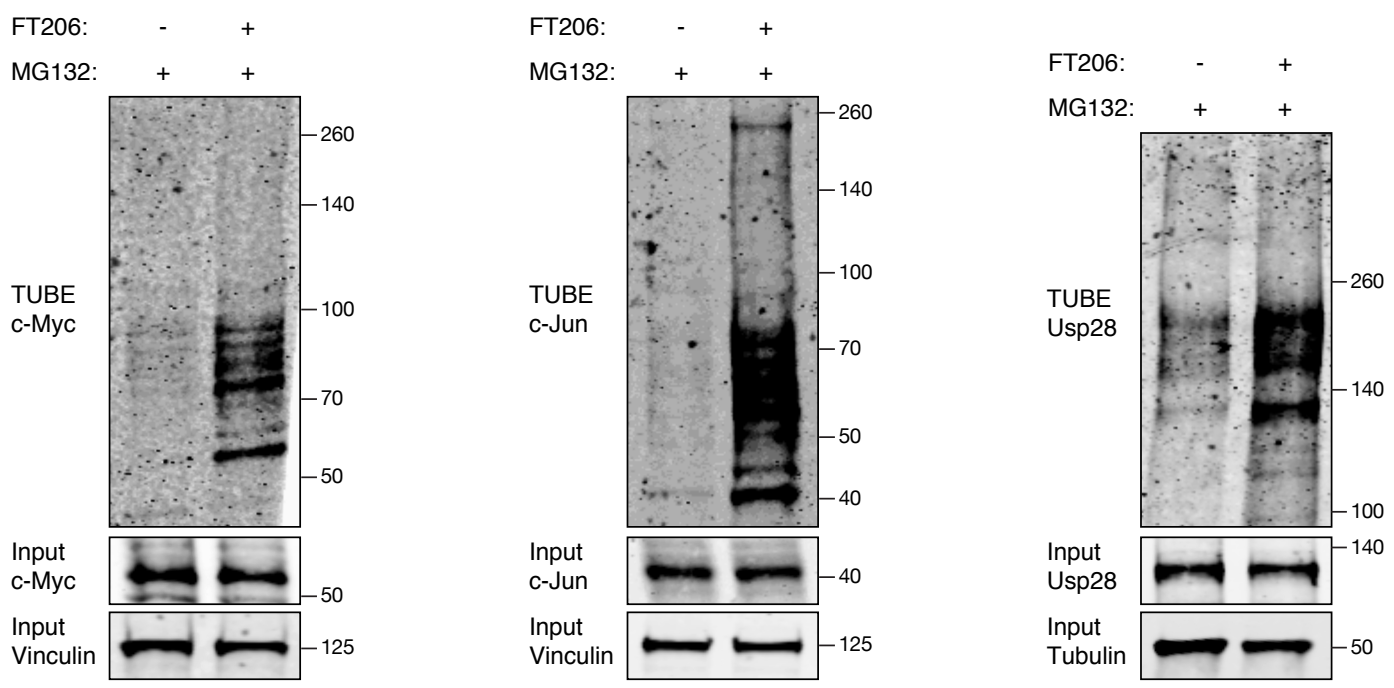

C

D
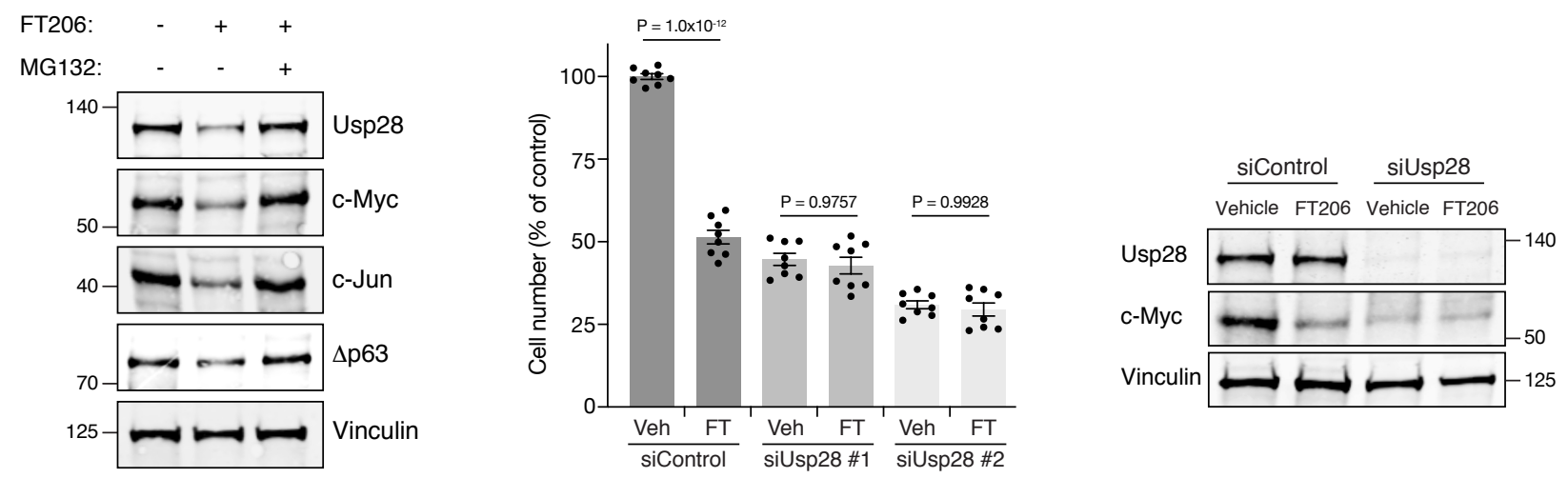

\section{Figure S4}


bioRxiv preprint doi: https://doi.org/10.1101/2020.11.17.377705; this version posted July 15, 2021. The copyright holder for this preprint (which was not certified by peer review) is the author/funder, who has granted bioRxiv a license to display the preprint in perpetuity. It is made available under 2 C-BY-NC-ND 4.0 International license.
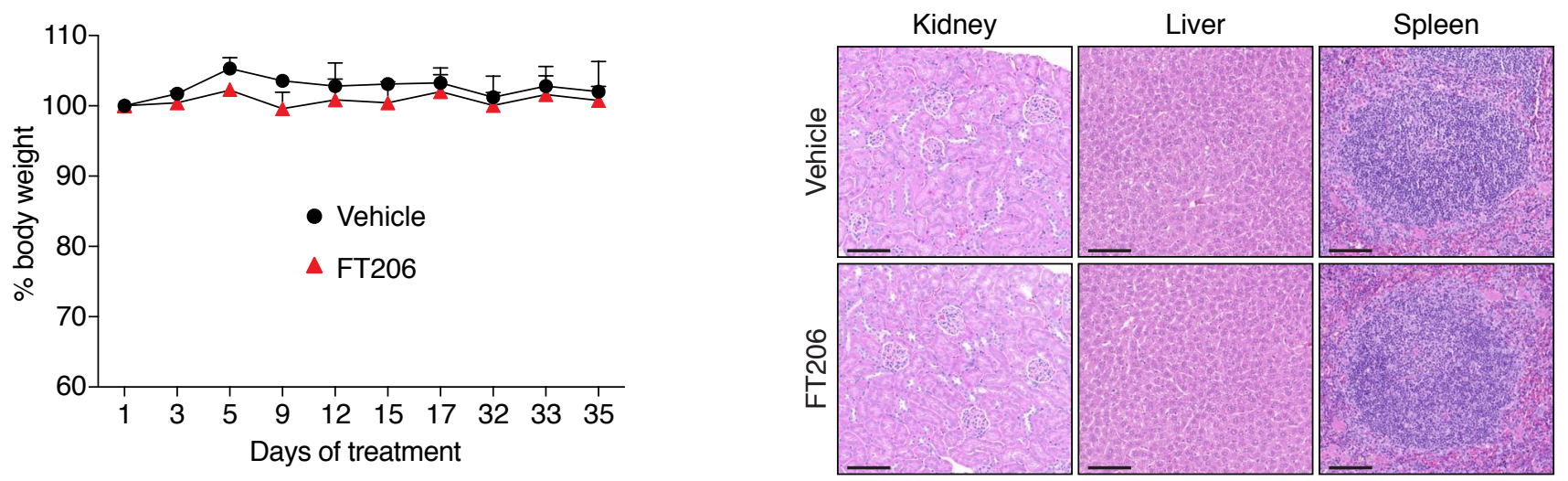

(which was not certified by peer review) is the author/funder, who has granted bioRxiv a license to display the preprint in perpetuity. It is made available under aCC-BY-NC-ND 4.0 International license.

\section{LSCC H520}

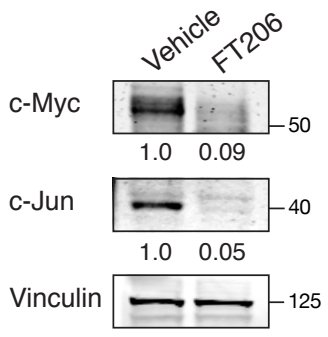

B

\section{LADC H23}

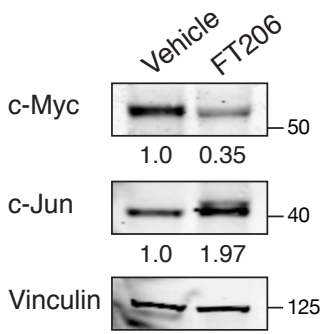

LSCC CALU-1

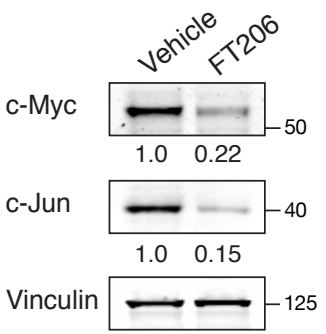

LADC H441

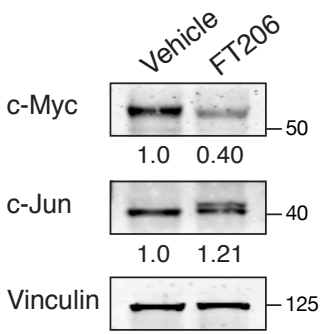

LSCC LUDLU-1

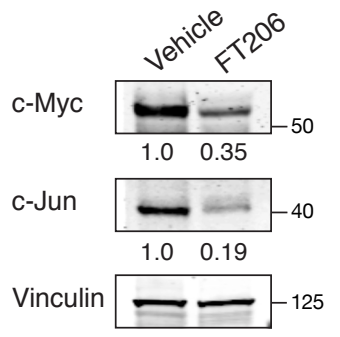

C

\begin{tabular}{|l|c|}
\hline Cell line & IC50 $(\mu \mathbf{M})$ \\
\hline \hline LSCC H520 & 0.1056 \\
\hline \hline LSCC CALU-1 & 0.2221 \\
\hline \hline LSCC LUDLU-1 & 0.3053 \\
\hline \hline LADC H23 & 0.3062 \\
\hline \hline LADC H441 & 1.25 \\
\hline \hline LADC H1650 & 0.3920 \\
\hline
\end{tabular}

